\title{
Occupation and working outcomes during the Coronavirus Pandemic
}

\author{
Agar Brugiavini $^{1} \cdot$ Raluca E. Buia $^{1}$ (D) - Irene Simonetti ${ }^{1}$
}

Accepted: 11 September 2021 / Published online: 8 October 2021

(c) The Author(s) 2021

\begin{abstract}
Using data from the first wave of the SHARE COVID-19 Survey and additional information collected from the previous waves of SHARE (Survey of Health Ageing and Retirement in Europe), we explore the effects of job characteristics on two outcomes: (i) the probability of work interruptions and (ii) the length of such interruptions during the first phase of the Coronavirus Pandemic. In order to assess the relationship between job features and labour market outcomes, we define two indexes proxying the pre-COVID-19 technical remote work feasibility as well as the level of social interaction with other people while working. Moreover, we use an indicator that classifies ISCO-08 3-digit job titles based on the essential nature of the good or service provided. We find that job characteristics have been major determinants of the probability of undergoing work interruptions and their duration. In addition, we show that women have been negatively affected by the Pandemic to a much larger extent than men, suggesting the relevance of the intrinsic characteristics of jobs they are mainly involved in, and the role of gender selection into specific activities. Not only females were more likely to have undergone work interruptions but they also exhibited larger probabilities of longer work breaks. A similar impact is seen for self-employed and less-educated workers.
\end{abstract}

Keywords Pandemic $\cdot$ Work interruption $\cdot$ Essential/unessential jobs $\cdot$ Remote work $\cdot$ Social interaction

JEL Classification J01 $\cdot \mathrm{J} 21 \cdot \mathrm{J} 24$

\section{Introduction}

The outbreak of the COVID-19 Pandemic at the beginning of 2020 led to radical changes in many aspects of individuals' lives. Mitigation policies, based on limiting social contacts and physical distancing, implied suspension, reduction and/ or converting several activities, including work, to remote mode. As shown by a series of indicators (OECD, Eurostat, 2020), the lockdown measures had enormous negative economic effects as well as changing several aspects of life, from the labour market activities to individuals' health and social behaviour. The available macroeconomic evidence documents a dramatic increase in unemployment (OECD, 2020a, 2020b) in spite of the joint efforts of governments

Responsible Editor: Matthias Kliegel.

Raluca E. Buia

elenabui@unive.it

1 Department of Economics, University Ca' Foscari of Venice, Venice, Italy and firms to prevent work interruptions by fostering - when possible-home working/teleworking (especially at the very beginning of the Pandemic) or by rearranging working spaces to maximize the physical distance. The OECD and ILO publications on employment trends indicate that low-qualified workers, individuals engaged in the informal economy, immigrants and women are the most vulnerable groups.

In the effort to identify the job-related drivers behind the negative effects of social distancing measures and mobility restrictions, the recent literature has focused on jobs that can be performed from home (WFH). Dingel and Neiman (2020) analyse occupations traits in the USA starting from the $\mathrm{O}$ *NET dictionary of occupations, while Yasonev (2020) investigates workers' characteristics, showing that young, low-educated and low-wage workers, as well as ethnic minorities and immigrants, are less likely to have jobs suitable for home working. Cetrulo et al. (2020) make use of the Italian INAPP-ICP data and find that marked occupational inequalities may result from the lockdown restrictions, with a high concentration of WHF jobs among managerial 
and executive categories, academics, technical professionals and clerical support workers as opposed to sales and service workers, manual operators, artisans and elementary occupations. In a cross-country study, Boeri et al. (2020) report that the percentage of jobs that can be performed remotely differs among European countries, from $23.95 \%$ in Italy to $31.38 \%$ in UK. A related line of investigation, developed before the Pandemic outbreak, has focused on some essential features of the tasks performed-(i) abstract, (ii) routine and (iii) manual—in order to explain occupational differences among workers (Autor and Dorn 2009; Autor and Dorn 2013; Deming 2017).

This evidence suggests the existence of high heterogeneity in measuring the consequences of the Coronavirus Pandemic on the labour market, which is partly due to general labour market conditions in a given country, partly to socioeconomic conditions and largely due to intrinsic characteristics of the job performed. Therefore, individual level data - especially on each job-are a crucial requirement to disentangle the role of these determinants. This paper investigates to what extent the type of occupation - and its peculiarities - drove individual's labour market consequences during the first wave of the Pandemic. Our analysis is relevant as it allows identifying workers who experienced the worst economic penalties due to the sanitary emergency, the most "vulnerable" activities. The interruption of working activity —either temporary or permanent — led to sizeable losses in terms of income, especially during the first phase of the Pandemic. Moreover, the longer the duration of the work interruption, the more likely it is to turn into "permanent" unemployment status at the end of the crisis, especially for the older age groups.

Recent data collected by the SHARE COVID-19 Survey allows for a detailed study of the changes in working conditions experienced by individuals aged 50 and over, as it contains information about respondents both before and during the COVID-19 outbreak. More precisely, we create a detailed dataset based on the pre-COVID-19 information available in panel format at the individual level in the ongoing SHARE survey, plus the information collected through the first wave of SHARE COVID-19 survey, and a classification of the occupations based on ISCO-08 3-digit codes.

Our approach is innovative as it deals with jobs traits allowing us to capture some crucial characteristics in a more parsimonious way. Based on Fasani and Mazza (2020), we first classify each ISCO-08 3-digit occupation according to the essential nature of goods and services provided. Moreover, by following Basso, Boeri, Caiumi, Paccagnella (2020) we generate two indexes for each code: (i) the remote work feasibility index measuring to what extent an occupation can be performed from home and (ii) the social interaction index assessing the intensity of social/physical contacts required in the workplace. These indexes are based on questions drawn from the Bureau of Labour Statistics (BLS) O*NET Survey data 2018, thus reflecting jobs features as if they were carried out in "normal times" (pre-COVID-19). In this way, we are able to distinguish between jobs that continued to be performed safely enough during the Pandemic because they usually involve a low level of social contact, and jobs that could potentially become safe because they suited remote working.

We model work continuity through an analysis in two steps. First, we estimate the effect of job characteristics on the probability of having experienced a temporary or permanent work interruption. Next, we assess the correlation between occupation traits and the length of interruptions. Our findings reveal that job characteristics have been major determinants of the probability of undergoing work interruptions as well as of their duration: unessential occupations are associated with a high prevalence of work interruptions, especially when unsuitable to be performed remotely or involve significant levels of social contacts. In addition, we show that women have been negatively affected by the Pandemic to a much larger extent than men. Females were more likely to experience work interruptions and longer work breaks. Our results point to the intrinsic characteristics of jobs performed by women, and the role of gender selection into specific activities, especially for female workers in older cohorts. Finally, we find that self-employed and lesseducated workers display larger probabilities of work breaks and longer interruptions.

The paper is organized as follows: "Data" section presents the data and relevant questions of the SHARE COVID19 questionnaire used in the analysis. "Empirical strategy" section describes the empirical specifications while "Results" section presents the results. "Conclusions" section concludes.

\section{Data}

We use information from the first wave of the SHARE COVID-19 Survey to assess how working conditions of Europeans aged 50 and over evolved during the first wave of the Coronavirus Pandemic. The data collection was carried out three to six month after the Pandemic outbreak, therefore, it overlaps with lockdown periods in some countries and possibly with periods when the lockdown measures were already lifted in some others. Our analysis focuses on individuals who report to have been working (as employed or self-employed) at the time of the COVID-19 outbreak. ${ }^{1}$

\footnotetext{
1 The employment status has been inferred from the SHARE COVID-19 Survey, question CAEP805_: "At the time when Corona broke out, were you employed or self-employed, including working for family business?".
} 
Fig. 1 Fractions of work interruption by country and gender

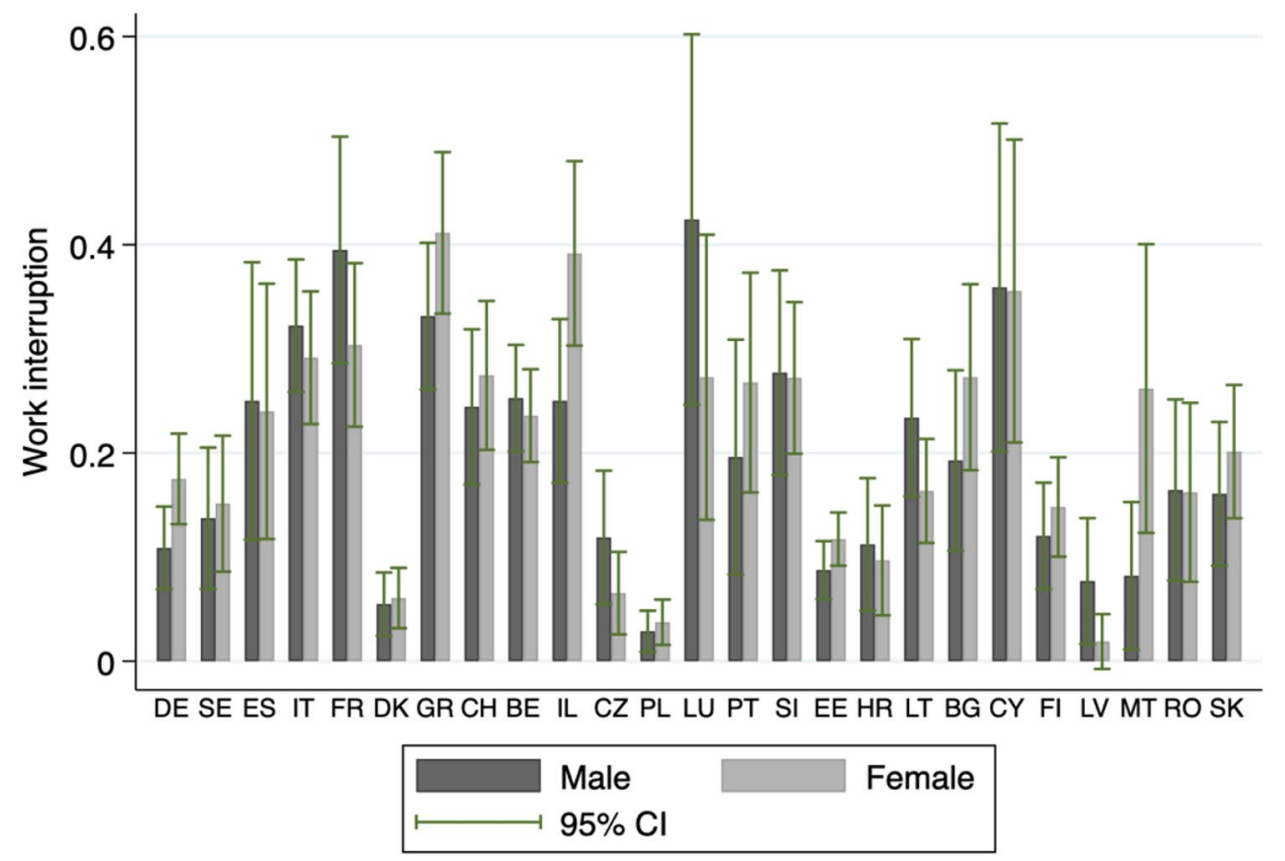

Source: Preliminary data SHARE wave 8 release 0 . Conclusions are preliminary.Notes: $95 \% \mathrm{Cl}$
Our final sample includes 7,619 people of which $44.30 \%$ are men, and $55.70 \%$ are women. ${ }^{2}$ Figure 1 in the supplementary material describes the sample composition by country and age groups.

\section{Working status during the Coronavirus Pandemic}

A first outcome of interest to develop our research question is the event "work interruption" experienced by the respondents during the first wave of the Pandemic. This outcome is elicited through the question: "Due to the Corona crisis have you become unemployed, were laid off or had to close your business?". Note that in this question respondents are instructed to answer "yes" also when they have only temporarily suspended their working activity. In order to estimate the parameters of interest, we define a categorical variable, which takes value one if the respondent reports work interruptions and value zero otherwise. The descriptive table provided in the supplementary material show that $18 \%$ of individuals in our sample declared a work interruption. Figure 1 shows the fraction of work interruptions by gender and country: significant heterogeneity emerges among countries and unconditional frequencies do not show any clear gender patterns.

The fraction of women who temporarily or permanently stopped their activity is particularly high in Israel and

\footnotetext{
2 We have dropped individuals from Hungary and the Netherlands because some relevant information is missing.
}

Greece but lower than for men in Luxembourg, Latvia and Lithuania. As we argued, in order to explain these patterns, one needs detailed information on the characteristics of the labour market and individual characteristics, including demographics and type of activities performed at work.

A second outcome is the intensive margin: i.e. the length of a work interruption, based on the question: "How long were you unemployed, laid off or had to close your business?" — measuring the number of weeks of interruption. This variable lends itself to different possible specifications, as we shall later explain. As a first approximation, we define a categorical variable taking three possible values: value zero if respondents continued working ( $82 \%$ of individuals), value one if they experienced a "short" interruption (around $11 \%$ of them experienced an interruption between 1 and 8 weeks) or value two if they stopped working for more than 8 weeks (7\%). ${ }^{3}$ Figure 2 describes the distributions of the length of respondents' work interruptions conditional on having undergone such events, by country and gender. The graph documents important differences between men and women-particularly strong in several countries such as the Czech Republic, Latvia, Spain or Sweden — as well as large heterogeneities among countries.

\footnotetext{
3 We set the threshold at 8 weeks as this is the median value of the variable CAW003_.
} 
Fig. 2 Length of work interruption by country and gender

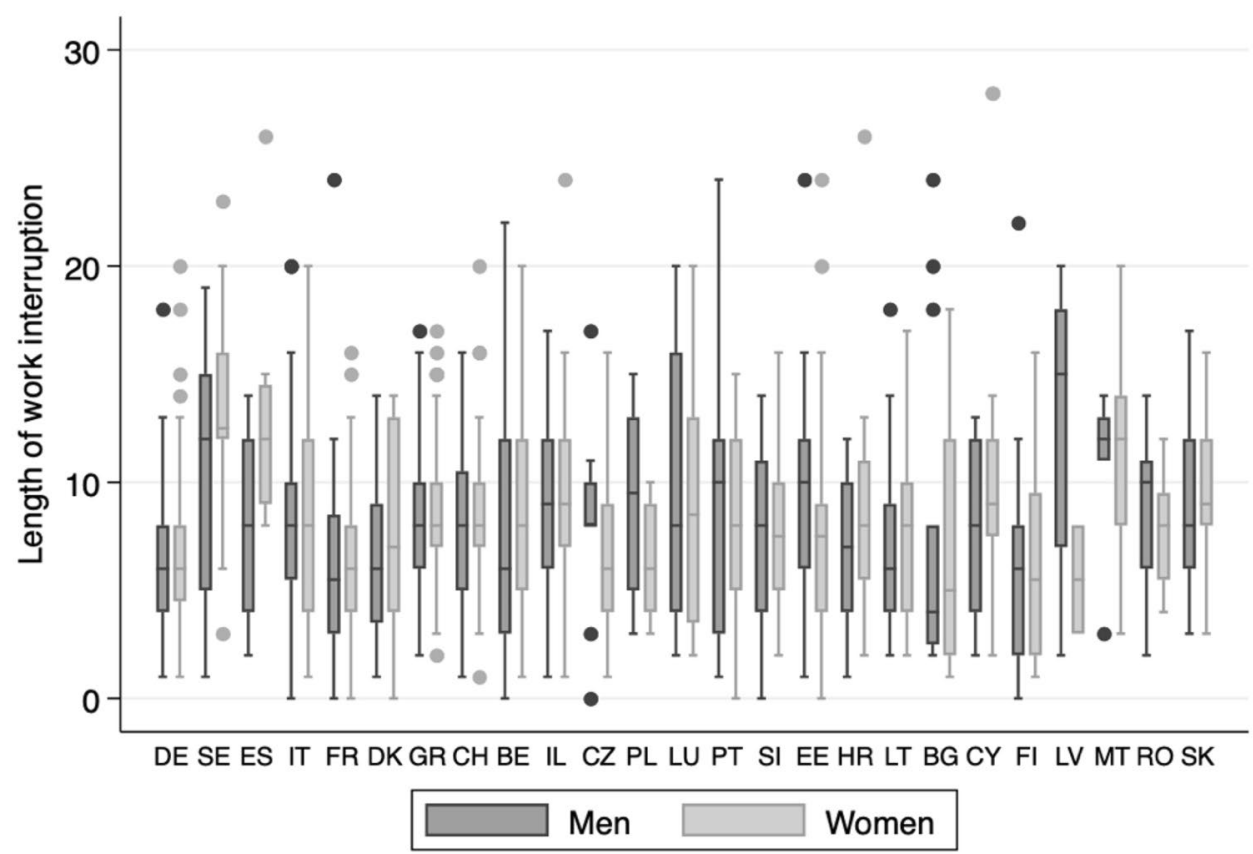

Source: Preliminary data SHARE wave 8 release 0 . Conclusions are preliminary.Notes: $95 \% \mathrm{Cl}$

\section{The role of the job characteristics}

The descriptive evidence provided in Fig. 1 outlines the major role of the Pandemic in changing individuals' working patterns. Differences in labour market experiences could be related to multiple factors: partly to the stringency of lockdown measures in a given country, partly to pre-pandemic socioeconomic conditions and largely to the intrinsic characteristics of the job. In this paper, we build a unique dataset by combining the SHARE COVID-19 Survey with information from the regular SHARE survey up to wave $8 .{ }^{4}$ This process allows us to create a detailed dataset of work characteristics before and during the Pandemic. The novelty relates to the use of the ISCO-08 3-digit codes associated with the job performed that are collected for working respondents in waves 6 through to $8 .^{5}$ This linkage provides us with a very large set of occupations from which we infer jobs characteristics, as well as details of tasks that workers are involved in.

However, potential drawbacks may arise from this wealth of information. Due to the density of the ISCO-08 codes (3-digit), the set of possible occupational titles is so wide

\footnotetext{
${ }^{4}$ Wave 8 was implemented right before the COVID-19 outbreak.

5 When respondents do not provide this type of information in wave 8 - either because they were not administered the regular questionnaire or because they had no change in their occupation since the previous interview - we recover their occupational code from the previous (most recent) wave in which they participated.
}

that some categories may not be well-represented. Moreover, the use of a full set of indicators in pooled estimations may also translate into a loss in degrees of freedom due to the large number of explanatory variables that need to be included ("curse of dimensionality"). It is worth recalling that we are looking at a sample of Europeans aged 50 and over, meaning that job characteristics potentially relevant for younger workers may not apply in our study.

To overcome these issues-while taking advantage of the richness of such a detailed job classification-we exploit multiple aspects related to occupations characteristics. First of all, we classify jobs according to a dimension that was deemed relevant during the COVID-19 Pandemic: the essential nature of goods or services produced and provided. This variable identifies workers who perform crucial tasks, spanning from highly skilled professionals such as doctors to low-skilled workers, like food processers. More precisely, we take advantage of the list of ISCO-08 3-digit codes as identified by Fasani and Mazza (2020) and available in Table $1 .{ }^{6}$ Secondly, by following Basso et al. (2020) methodology, we built two indexes meant to measure two key features of occupations: (i) the extent to which an occupation could be technically performed from home and (ii) a

\footnotetext{
6 The list is based on the "Communication from the Commission on Guidelines concerning free movements of workers" during the first wave of the COVID-19 outbreak (https://ec.europa.eu/social/main. jsp?langId=en\&catId $=89 \&$ furtherNews=yes\&newsId $=9630)$ and the Dutch definition of key workers (https://www.government.nl/topics/ coronavirus-covid-19).
} 
Table 1 Essential jobs by ISCO-08 3-digit codes

\begin{tabular}{|c|c|}
\hline ISCO-08 3-digit & Occupation \\
\hline 213 & Life Science Professionals \\
\hline 214 & Engineering Professionals (excluding Electrotechnology) \\
\hline 221 & Medical Doctors \\
\hline 222 & Nursing and Midwifery Professionals \\
\hline 223 & Traditional and Complementary Medicine Professionals \\
\hline 224 & Paramedical Practitioners \\
\hline 226 & Other Health Professionals \\
\hline 231 & University and Higher Education Teachers \\
\hline 232 & Vocational Education Teachers \\
\hline 233 & Secondary Education Teachers \\
\hline 234 & Primary School and Early Childhood Teachers \\
\hline 235 & Other Teaching Professionals \\
\hline 251 & Software and Applications Developers and Analysts \\
\hline 252 & Database and Network Professionals \\
\hline 311 & Physical and Engineering Science Technicians \\
\hline 312 & Mining, Manufacturing and Construction Supervisors \\
\hline 313 & Process Control Technicians \\
\hline 314 & Life Science Technicians and Related Associate Professionals \\
\hline 315 & Ship and Aircraft Controllers and Technicians \\
\hline 321 & Medical and Pharmaceutical Technicians \\
\hline 322 & Nursing and Midwifery Associate Professionals \\
\hline 351 & $\begin{array}{l}\text { Information and Communications Technology Operations and } \\
\text { User Support Technicians }\end{array}$ \\
\hline 352 & Telecommunications and Broadcasting Technicians \\
\hline 511 & Travel Attendants, Conductors and Guides \\
\hline 516 & Other Personal Services Workers \\
\hline 531 & Child Care Workers and Teachers' Aides \\
\hline 532 & Personal Care Workers in Health Services \\
\hline 611 & Market Gardeners and Crop Growers \\
\hline 612 & Animal Producers \\
\hline 613 & Mixed Crop and Animal Producers \\
\hline 751 & Food Processing and Related Trades Workers \\
\hline 816 & Food and Related Products Machine Operators \\
\hline 831 & Locomotive Engine Drivers and Related Workers \\
\hline 832 & Car, Van and Motorcycle Drivers \\
\hline 833 & Heavy Truck and Bus Drivers \\
\hline 835 & Ships' Deck Crews and Related Workers \\
\hline 911 & Domestic, Hotel and Office Cleaners and Helpers \\
\hline 912 & Vehicle, Window, Laundry and Other Hand Cleaning Workers \\
\hline 933 & Transport and Storage Labourers \\
\hline 961 & Refuse Workers \\
\hline
\end{tabular}

Source: Fasani and Mazza (2020)

measure of the level of social interaction when performing the job. Both indices are generated at an ISCO-08 3-digit level, using pre COVID-19 data elicited from the Bureau of
Labour Statistics (BLS) O*NET Survey data 2018. Thus, it is worth emphasising that they are built on pre-pandemic characteristics, that is, the way jobs were carried out in "normal times". ${ }^{7}$

7 We refer to Basso et al. (2020) for the detailed list of selected questions and value-thresholds. 
The Bureau of Labour Statistics (BLS) O*NET Survey data 2018 provides a detailed description of work traits for each job in the USA ("work activities" and "work context"). ${ }^{8}$ Based on a broad range of questions, Basso et al. (2020) define four groups of occupations, capturing different "degrees of safeness" in the workplace and classify each ISCO-08 3-digit code accordingly. The most restrictive definition of safeness includes jobs potentially performed remotely (category 1). The second and third categories relax the previous definition and incorporate, besides the occupations in the first class, also jobs with a 'low physical proximity and limited exposure to customers and to the public' (category 2) and jobs with a "higher degree of interactions with external customers, but the level of physical proximity remains low" (category 3 ). ${ }^{9}$ The fourth group is a residual class-labelled as "unsafe jobs"-including all the remaining jobs with a relatively high risk of contagion. Although we use the same set of O*NET questions and thresholds, we do not stick to their definition of safeness. We completely separate the concepts of remote work feasibility and level of social interactions by defining two distinct indexes ranging between 0 and 1 :

- The remote work feasibility index measures the extent to which a specific activity is suitable for remote work. We construct it using the same procedure and the same questions elicited by Basso et al. (2020) to describe the importance of physical/computer-based tasks in each job. ${ }^{10} \mathrm{~A}$ value equal to 0 means that a job cannot be performed at home (e.g. "primary school and early childhood teachers" (234), "medical doctors" (221) or "domestic, hotel and office cleaners and helpers" (911)), while a value of 1 is associated to ISCO-08 codes suited perfectly to home working from a technical point of view (e.g. "finance professionals" (241) or "legal professionals" (261)).

- The social interaction at work index proxies the level of physical and social interaction with other people while working. It is built on questions regarding the physical proximity to other persons, the importance of interactions with the public and the frequency of exposure to diseases or infection.

\footnotetext{
8 This methodology maps US jobs' characteristics, namely their technology and labour market conditions, into European jobs. This exercise entails some measurement error as long as technology differs across countries and European occupations. Thus, the results need to be interpreted as if the US occupational technology was in place for each labour market analysed (Basso et al. (2020)).

${ }^{9}$ Hence, category 1 is a subset of category 2, while category 2 is a subset of category 3 .

10 Eighteen questions are drawn from the "work context" module while nine are selected from the "work activities" section.
}

Table 2 displays the values of these two indexes for each ISCO-08 3-digit job. Interestingly, we do not find a defined pattern characterising these measures: while some occupations display high remote work feasibility and low social contacts (e.g. legal professionals), others are technically teleworkable but would normally require intensive social interactions (for example 233 - secondary education teachers). This is also easily observed in Fig. 3, which matches the two indexes for a selection of ISCO-08 sub-majors in the left panel and for several ISCO-08 3-digit codes in the right panel. This comparison gives an idea of the significant heterogeneity, which exists among occupations even within the same sub-major. For instance, important differences appear when looking at professional teachers (23) and their detailed decomposition by 3 -digit codes. University and higher education teachers (231) display high remote work feasibility and mild social contacts, but primary school and early childhood teachers (234) on the other hand, require strong interactions with children. Furthermore, secondary school teachers (233) would normally require intensive social interactions yet have features which are well suited to home working.

All these examples reveal the importance of using detailed job information in order to better understand the role of job characteristics during the first wave of the Pandemic.

\section{Empirical strategy}

Our paper enquires about individuals' working experiences during the Pandemic: more specifically having undergone work interruption spells and the length of such episodes. We perform the analysis in two steps: first, we estimate the effect of occupation on the probability of having experienced work interruptions (temporary or permanent) using a probit regression; second, we analyse the correlation between the job features and the length of such spells by running an ordered probit specification.

A simple regression model for both outcomes is given in Eq. (1):

$$
\begin{aligned}
y_{i}= & \alpha+\beta_{1} \text { Essential }_{i}+\beta_{2} \text { RemoteWorkIndex }_{i} \\
& +\beta_{3} \text { SocialInter_Index }_{\mathrm{i}}+\beta_{4} \text { Essential }_{\mathrm{i}} * \operatorname{Re} \text { moteWorkIndex } \\
& +\beta_{5} \text { Essential }_{\mathrm{i}} * \text { SocialInter_Index }_{\mathrm{i}}+X_{\mathrm{i}}^{\prime}+\rho_{\mathrm{c}}+u_{\mathrm{i}}
\end{aligned}
$$

In the first specification, the dependent variable $y_{i}$ is a binary variable taking the value of 1 if the respondent has experienced work interruptions and 0 otherwise. When estimating the length of work breaks we define $y_{i}$ as a categorical ordered variable based on the number of weeks of interruption reported by the respondent. In this case, the dependent variable $y_{i}$ takes value of 0 if no interruptions 
Table 2 Remote work feasibility and social interaction indexes by ISCO-08 3-digit codes

\begin{tabular}{|c|c|c|c|}
\hline ISCO-08 3-digit & Occupation & $\begin{array}{l}\text { Remote work } \\
\text { feasibility }\end{array}$ & Social interaction \\
\hline 111 & Legislators and Senior Officials & 0,970 & 0,853 \\
\hline 112 & Managing Directors and Chief Executives & 1 & 0,912 \\
\hline 121 & Business Services and Administration Managers & 0,971 & 0,528 \\
\hline 122 & Sales, Marketing and Development Managers & 0,875 & 0,489 \\
\hline 131 & Production Managers in Agriculture, Forestry and Fisheries & 0 & 0,667 \\
\hline 132 & Manufacturing, Mining, Construction and Distribution Managers & 0,289 & 0,413 \\
\hline 133 & Information and Communications Technology Services Managers & 1 & 0 \\
\hline 134 & Professional Services Managers & 0,731 & 0,616 \\
\hline 141 & Hotel and Restaurant Managers & 0 & 1 \\
\hline 142 & Retail and Wholesale Trade Managers & 1,000 & 1 \\
\hline 143 & Other Services Managers & 0,743 & 0,469 \\
\hline 211 & Physical and Earth Science Professionals & 0,481 & 0,055 \\
\hline 212 & Mathematicians, Actuaries and Statisticians & 1,000 & 0 \\
\hline 213 & Life Science Professionals & 0,619 & 0,309 \\
\hline 214 & Engineering Professionals (excluding Electrotechnology) & 0,428 & 0,157 \\
\hline 215 & Electrotechnology Engineers & 0,824 & 0,000 \\
\hline 216 & Architects, Planners, Surveyors and Designers & 0,672 & 0,459 \\
\hline 221 & Medical Doctors & 0 & 1 \\
\hline 222 & Nursing and Midwifery Professionals & 0 & 1 \\
\hline 223 & Traditional and Complementary Medicine Professionals & 0 & 1 \\
\hline 224 & Paramedical Practitioners & 0 & 1 \\
\hline 225 & Veterinarians & 0 & 1 \\
\hline 226 & Other Health Professionals & 0 & 1 \\
\hline 231 & University and Higher Education Teachers & 0,905 & 0,555 \\
\hline 232 & Vocational Education Teachers & 0,060 & 1 \\
\hline 233 & Secondary Education Teachers & 1 & 1 \\
\hline 234 & Primary School and Early Childhood Teachers & 0 & 1 \\
\hline 235 & Other Teaching Professionals & 0,420 & 0,787 \\
\hline 241 & Finance Professionals & 1,000 & 0,445 \\
\hline 242 & Administration Professionals & 0,752 & 0,289 \\
\hline 243 & Sales, Marketing and Public Relations Professionals & 1 & 0,214 \\
\hline 251 & Software and Applications Developers and Analysts & 1 & 0 \\
\hline 252 & Database and Network Professionals & 1 & 0 \\
\hline 261 & Legal Professionals & 1 & 1 \\
\hline 262 & Librarians, Archivists and Curators & 0,879 & 0,938 \\
\hline 263 & Social and Religious Professionals & 0,084 & 0,937 \\
\hline 264 & Authors, Journalists and Linguists & 0,796 & 0,439 \\
\hline 265 & Creative and Performing Artists & 0,633 & 0,903 \\
\hline 311 & Physical and Engineering Science Technicians & 0 & 0,240 \\
\hline 312 & Mining, Manufacturing and Construction Supervisors & 0 & 1 \\
\hline 313 & Process Control Technicians & 0 & 0,862 \\
\hline 314 & Life Science Technicians and Related Associate Professionals & 0 & 0,455 \\
\hline 315 & Ship and Aircraft Controllers and Technicians & 0 & 0,824 \\
\hline 321 & Medical and Pharmaceutical Technicians & 0 & 1 \\
\hline 322 & Nursing and Midwifery Associate Professionals & 0 & 1 \\
\hline 323 & Traditional and Complementary Medicine Associate Professionals & 0 & 1 \\
\hline 324 & Veterinary Technicians and Assistants & 0 & 1 \\
\hline 325 & Other Health Associate Professionals & 0,113 & 0,905 \\
\hline 331 & Financial and Mathematical Associate Professionals & 0,959 & 0,940 \\
\hline
\end{tabular}


Table 2 (continued)

ISCO-08 3-digit Occupation
Remote work Social interaction feasibility

\begin{tabular}{|c|c|c|c|}
\hline 332 & Sales and Purchasing Agents and Brokers & 1 & 0,592 \\
\hline 333 & Business Services Agents & 0,513 & 0,533 \\
\hline 334 & Administrative and Specialized Secretaries & 0,797 & 0,920 \\
\hline 335 & Government regulatory associate professionals & 0,364 & 0,886 \\
\hline 341 & Legal, Social and Religious Associate Professionals & 0,496 & 0,917 \\
\hline 342 & Sports and Fitness Workers & 0,136 & 1 \\
\hline 343 & Artistic, Cultural and Culinary Associate Professionals & 0,073 & 0,974 \\
\hline 351 & Information and Communications Technology Operations and User Support Technicians & 1 & 0,577 \\
\hline 352 & Telecommunications and Broadcasting Technicians & 0,078 & 0,597 \\
\hline 411 & General Office Clerks & 1 & 0,978 \\
\hline 412 & Secretaries (general) & 1 & 0 \\
\hline 413 & Keyboard Operators & 1 & 0,233 \\
\hline 421 & Tellers, Money Collectors and Related Clerks & 0,833 & 0,737 \\
\hline 422 & Client Information Workers & 0,403 & 0,989 \\
\hline 431 & Numerical Clerks & 1 & 0,860 \\
\hline 432 & Material recording and Transport Clerks & 0,101 & 0,492 \\
\hline 441 & Other Clerical Support Workers & 0,242 & 0,848 \\
\hline 511 & Travel Attendants, Conductors and Guides & 0,092 & 1 \\
\hline 512 & Cooks & 0 & 1 \\
\hline 513 & Waiters and Bartenders & 0 & 1 \\
\hline 514 & Hairdressers, Beauticians and Related Workers & 0,032 & 1 \\
\hline 515 & Building and Housekeeping Supervisors & 0 & 0,177 \\
\hline 516 & Other Personal Services Workers & 0,047 & 1 \\
\hline 521 & Street and Market Salespersons & 0,023 & 1 \\
\hline 522 & Shop Salespersons & 0,258 & 1 \\
\hline 523 & Cashiers and Ticket Clerks & 0 & 1 \\
\hline 524 & Other Sales Workers & 0,083 & 1 \\
\hline 531 & Child Care Workers and Teachers' Aides & 0,008 & 1 \\
\hline 532 & Personal Care Workers in Health Services & 0,005 & 1 \\
\hline 541 & Protective Services Workers & 0 & 1 \\
\hline 611 & Market Gardeners and Crop Growers & 0 & 0,488 \\
\hline 612 & Animal Producers & 0 & 0,215 \\
\hline 613 & Mixed Crop and Animal Producers & 0 & 0,079 \\
\hline 621 & Forestry and Related Workers & 0 & 0,282 \\
\hline 622 & Fishery Workers, Hunters and Trappers & 0 & 0,215 \\
\hline 631 & Subsistence Crop Farmers & 0 & 0,500 \\
\hline 632 & Subsistence Livestock Farmers & 0 & 1 \\
\hline 633 & Subsistence Mixed Crop and Livestock Farmers & 0 & 0,558 \\
\hline 711 & Building Frame and Related Trades Workers & 0 & 1 \\
\hline 712 & Building Finishers and Related Trades Workers & 0 & 0,848 \\
\hline 713 & Painters, Building Structure Cleaners and Related Trades Workers & 0 & 0,823 \\
\hline 721 & Sheet and Structural Metal Workers, Moulders and Welders, and Related Workers & 0 & 0,416 \\
\hline 722 & Blacksmiths, Toolmakers and Related Trades Workers & 0 & 0,034 \\
\hline 723 & Machinery Mechanics and Repairers & 0 & 0,379 \\
\hline 731 & Handicraft Workers & 0,037 & 0,515 \\
\hline 732 & Printing Trades Workers & 0,157 & 0 \\
\hline 741 & Electrical Equipment Installers and Repairers & 0 & 0,968 \\
\hline 742 & Electronics and Telecommunications Installers and Repairers & 0 & 0,991 \\
\hline 751 & Food Processing and Related Trades Workers & 0 & 0,588 \\
\hline
\end{tabular}


Table 2 (continued)

ISCO-08 3-digit Occupation
Remote work Social interaction feasibility

\begin{tabular}{|c|c|c|c|}
\hline 752 & Wood Treaters, Cabinet-makers and Related Trades Workers & 0 & 0,510 \\
\hline 753 & Garment and Related Trades Workers & 0 & 0,426 \\
\hline 754 & Other Craft and Related Workers & 0 & 1 \\
\hline 811 & Mining and Mineral Processing Plant Operators & 0 & 0,380 \\
\hline 812 & Metal Processing and Finishing Plant Operators & 0 & 0,338 \\
\hline 813 & Chemical and Photographic Products Plant and Machine Operators & 0 & 0,157 \\
\hline 814 & Rubber, Plastic and Paper Products Machine Operators & 0 & 0,307 \\
\hline 815 & Textile, Fur and Leather Products Machine Operators & 0 & 0,589 \\
\hline 816 & Food and Related Products Machine Operators & 0 & 0,266 \\
\hline 817 & Wood Processing and Papermaking Plant Operators & 0 & 0 \\
\hline 818 & Other Stationary Plant and Machine Operators & 0 & 0,046 \\
\hline 821 & Assemblers & 0 & 0,444 \\
\hline 831 & Locomotive Engine Drivers and Related Workers & 0 & 0,451 \\
\hline 832 & Car, Van and Motorcycle Drivers & 0 & 1 \\
\hline 833 & Heavy Truck and Bus Drivers & 0 & 1 \\
\hline 834 & Mobile Plant Operators & 0 & 0,165 \\
\hline 835 & Ships' Deck Crews and Related Workers & 0 & 1 \\
\hline 911 & Domestic, Hotel and Office Cleaners and Helpers & 0 & 0,504 \\
\hline 912 & Vehicle, Window, Laundry and Other Hand Cleaning Workers & 0 & 0,028 \\
\hline 921 & Agricultural, Forestry and Fishery Labourers & 0 & 0,953 \\
\hline 931 & Mining and Construction Labourers & 0 & 0,992 \\
\hline 932 & Manufacturing Labourers & 0 & 0,715 \\
\hline 933 & Transport and Storage Labourers & 0 & 0,869 \\
\hline 941 & Food Preparation Assistants & 0 & 1 \\
\hline 952 & Street Vendors (excluding Food) & 1 & 1 \\
\hline 961 & Refuse Workers & 0 & 1 \\
\hline 962 & Other Elementary Workers & 0,010 & 0,949 \\
\hline
\end{tabular}
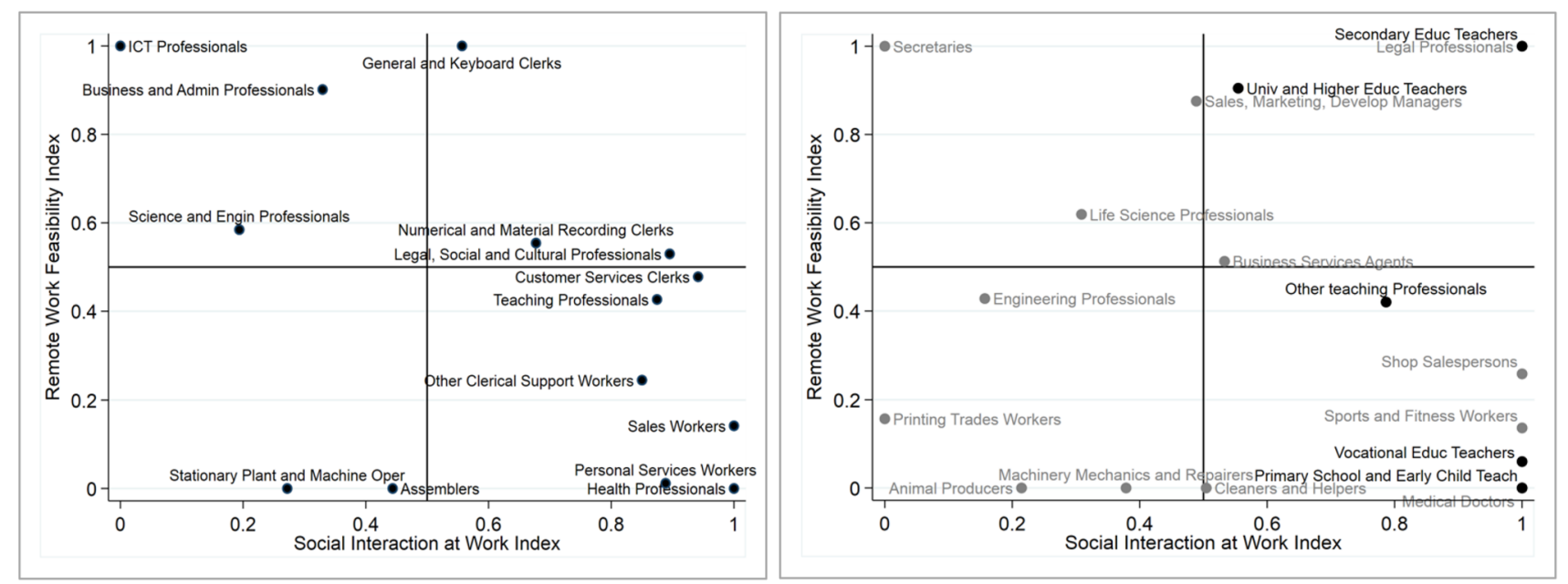

Data: Preliminary SHARE wave 8 release 0 . Conclusions are preliminary.

Fig. 3 Remote work feasibility and social interaction indexes on a selection of ISCO-08 2-digit codes (left panel), and ISCO-08 3-digit codes (right panel) 
were declared, value of 1 if the respondent stopped his/ her working activity for at most 8 weeks and a value of 2 if the interruption lasted for more than 8 weeks. The key explanatory variables are the occupation specific variables: the two indexes measuring the remote work feasibility (RemoteWorkIndex ${ }_{i}$ ) and the intensity of social interaction $($ SocialInter_Index $i)$, as well as an indicator variable that identifies the essential occupations $\left(\right.$ Essential $\left._{i}=1\right)$. The use of pre-COVID-19 questions about job characteristics enables us to overcome possible endogeneity concerns between job features and work outcomes during the Pandemic.

In all the specifications we control also for other determinants concerning workers and work environment. A particularly relevant variable is the self-evaluated IT skills of the individual-which is recovered from the previous waves of SHARE. We also control for a set of socioeconomic and demographic variables, such as gender, age, education, health status (whether the individual experienced major illnesses immediately before the Pandemic), whether the individual used to work as a private employee, public sector employee or was self-employed. Moreover, in order to account for heterogeneities among countries-both in terms of lockdown measures as well as economic background-we include country fixed-effect dummy variables $\left(\rho_{c}\right)$.

\section{Results}

\section{Occupation, work interruption and work arrangements during the Pandemic}

Table 3 reports the marginal effects of the probability of work interruptions for two specifications: the first columnmodel 1 -is a parsimonious specification in which, besides the occupation specific variables (i.e. the essential nature of a job, the remote work feasibility index and the social interaction index), we include gender, age and country of residence. In model 2, we also control for education, information technology skills, type of employment and health status.

Our results point out job characteristics as major determinants of the probability to experience work interruptions during the first-unexpected-wave of the Pandemic. Indeed, individuals employed in "essential" activities were 3.5 percentage points less likely to have gone through work breaks than those working in "unessential" jobs. In relative terms, with respect to the average sample probability of $17.9 \%$, individuals employed in essential jobs were $19.5 \%$ less likely to experience interruptions with respect to nonessential employees. The marginal effects of the two indexes reveal that increasing suitability of remote work is associated with a significantly lower probability of work interruptions, while the higher the level of social interaction in the
Table 3 Probit model: work interruption probability

\begin{tabular}{|c|c|c|}
\hline & \multicolumn{2}{|c|}{ Work Interruption } \\
\hline & Baseline model & Full model \\
\hline Essential Jobs & $\begin{array}{l}-0.061 * * * \\
(0.009)\end{array}$ & $\begin{array}{l}-0.035^{* * *} \\
(0.01)\end{array}$ \\
\hline Remote Work Feasibility Index & $\begin{array}{l}-0.119^{* * *} \\
(0.012)\end{array}$ & $\begin{array}{l}-0.078^{* * *} \\
(0.014)\end{array}$ \\
\hline Social Interaction Index & $\begin{array}{l}0.009 \\
(0.014)\end{array}$ & $\begin{array}{l}0.036^{* *} \\
(0.015)\end{array}$ \\
\hline Age & $\begin{array}{l}0.001 \\
(0.001)\end{array}$ & $\begin{array}{l}0.0003 \\
(0.001)\end{array}$ \\
\hline Female & $\begin{array}{l}0.023 * * * \\
(0.009)\end{array}$ & $\begin{array}{l}0.039 * * * \\
(0.009)\end{array}$ \\
\hline \multicolumn{3}{|l|}{ High School Education (baseline) } \\
\hline Less than high school & - & $\begin{array}{l}0.030 * * \\
(0.016)\end{array}$ \\
\hline Higher than high school & - & $\begin{array}{l}-0.035^{* * *} \\
(0.011)\end{array}$ \\
\hline Major Illness & - & $\begin{array}{l}0.02 \\
(0.017)\end{array}$ \\
\hline \multicolumn{3}{|l|}{ Medium level of IT- skills (baseline) } \\
\hline High IT- skills & - & $\begin{array}{l}-0.005 \\
(0.011)\end{array}$ \\
\hline Low IT- skills & - & $\begin{array}{l}0.007 \\
(0.013)\end{array}$ \\
\hline \multicolumn{3}{|l|}{ Private Employee (baseline) } \\
\hline Public employee & - & $\begin{array}{l}-0.083^{* * * *} \\
(0.01)\end{array}$ \\
\hline Self- employed & - & $\begin{array}{l}0.064 * * * \\
(0.016)\end{array}$ \\
\hline Essential_RemoteWorkIndex & Yes & Yes \\
\hline Essential_SocialInteractionIndex & Yes & Yes \\
\hline Country dummies & Yes & Yes \\
\hline $\mathrm{N}$ & 7619 & 6878 \\
\hline Pseudo-r2 & 0.0925 & 0.1086 \\
\hline Log pseudolikelihood & -3246.16 & -2910.38 \\
\hline
\end{tabular}

Data: Preliminary SHARE wave 8 release 0 . Conclusions are preliminary.

Note: Average marginal effects of probit models are reported. Drop of observations in full model is due to missing values in additional explanatory variables.

${ }^{*} p<0.1, * * p<0.05, * * * p<0.01$

workplace, the larger the likelihood of experiencing work breaks. ${ }^{11}$ Figure 4 provides additional insights by displaying

\footnotetext{
$\overline{11}$ In relative terms, an increase of 10 percentage points in the remote work feasibility and social interaction indexes, determine a reduction of the probability of experiencing work interruptions of about $4.36 \%$ in the first case, while an increase of about $2.01 \%$ in the second case.
} 
Fig. 4 Work interruption probability: average marginal effects of working in essential jobs at different levels of the remote work feasibility and social interaction indexes

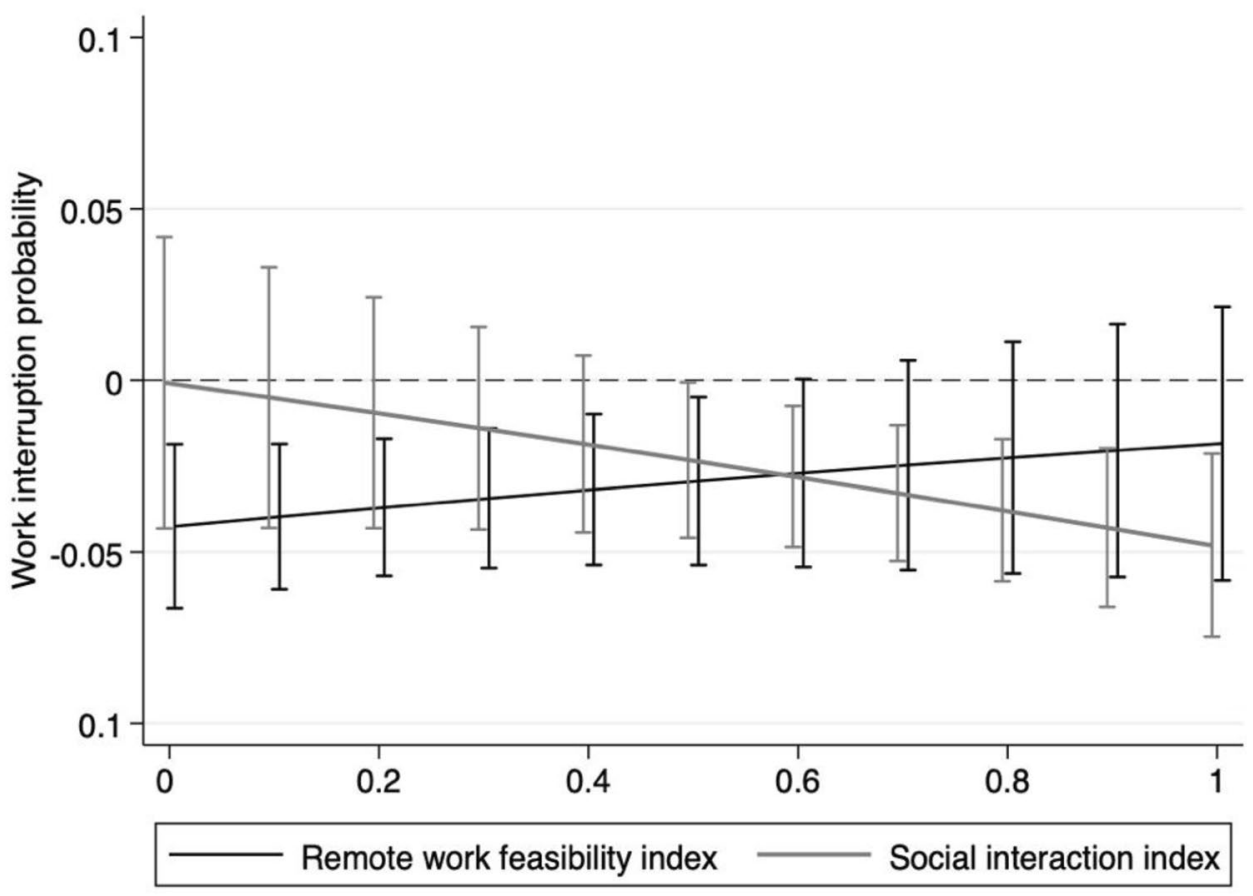

Source: Preliminary data SHARE wave 8 release 0 . Conclusions are preliminary. Notes: $95 \% \mathrm{Cl}$ the marginal effects of an essential job at various levels of remote work feasibility index and social interaction index.

It is worth noticing that, for values of the remote working feasibility index smaller than 0.6 (representing little or modest home working suitability), being an essential occupation is associated with significantly lower probabilities of experiencing work interruptions. The positive slope suggests that, as the technical teleworkability of a job increases, the gap between essential and unessential occupations gets smaller with respect to the likelihood of work breaks during the Pandemic. An opposite relationship is found when looking at the social interaction index: jobs characterized by a low intensity of interaction between people display no significant differences between essential and unessential activities. On the contrary, as the level of social contact becomes more important, the difference between the two categories increases (i.e. essential jobs display lower probabilities of work interruption).

One could argue that the three selected job characteristics (i.e. essential/unessential plus the two indexes) might be arbitrary and conceal useful information because they are based on criteria reflecting the COVID-19 Pandemic. Indeed, as the Pandemic occurred, some jobs became more relevant than others and at the same time, some occupations were more prone to home working or less risky in terms of social interaction intensity. In order to show that our proposed measures preserve the value of the original information, we carried out a robustness check (see Table 4) by estimating Eq. (1) with forty dummy variables, one for each job sub-major. Note that in this setup sometimes we treat in a unique group rather heterogeneous occupations, due to how the ISCO-08 2-digit classification clusters jobs. For example, we cannot distinguish between sellers of food ("essential" goods) and those vending other commodities. ${ }^{12}$

We choose "teaching professionals" as the baseline group due to their fairly homogeneous nature in terms of work arrangements options during the Pandemic: most teaching activities continued remotely in almost every European country. With respect to the baseline group, the coefficients show that jobs belonging to other sub-majors had significantly higher probabilities of temporary or permanent work interruptions. Larger and statistically significant effects are associated with occupations related to tourism and hospitality, while jobs in "subsistence agricultural activities" were found to have a lower probability of interruptions. These results are in line with our main specifications.

Table 5 reports the marginal effects of two ordered probit models for the length of work interruptions. Individuals working in essential occupations were about $1.3-1.6$ percentage points less likely to experience longer work interruptions (columns 2 and 3 respectively) and more likely to go through brief episodes (less than 1 week) or no activity

\footnotetext{
12 The only possibility to distinguish between different types of sellers (by using dummies for job categories) would be to use a much higher level of detail, such as 4-digit ISCO-08. Moreover, the distinction between those working in food shops and other types of sellers would need to go even deeper, that is, to occupation titles.
} 
Table 4 Work Interruption probability by ISCO-08 2-digits

\begin{tabular}{|c|c|c|c|c|c|}
\hline & Baseline model & Full model & (continue) & Baseline model & Full model \\
\hline \multicolumn{6}{|l|}{$\begin{array}{l}\text { 23.Teaching professionals (BASELINE } \\
\text { GROUP) }\end{array}$} \\
\hline \multirow{2}{*}{$\begin{array}{l}\text { 11.Chief Executives, Senior Officials and } \\
\text { Legislators }\end{array}$} & $0.066^{* *}$ & 0.036 & & & \\
\hline & $(0.030)$ & $(0.032)$ & & & \\
\hline \multirow{2}{*}{$\begin{array}{l}\text { 12.Administrative and Commercial } \\
\text { Managers }\end{array}$} & $0.071 * *$ & 0.038 & 53.Personal Care Workers & $0.121 * * *$ & $0.096 * * *$ \\
\hline & $(0.028)$ & $(0.031)$ & & $(0.024)$ & $(0.028)$ \\
\hline \multirow{2}{*}{$\begin{array}{l}\text { 13.Production and Specialized Services } \\
\text { Managers }\end{array}$} & 0.041 & 0.013 & 54.Protective Services Workers & $0.123 * *$ & $0.103 * *$ \\
\hline & $(0.026)$ & $(0.029)$ & & $(0.038)$ & $(0.042)$ \\
\hline \multirow[t]{2}{*}{$\begin{array}{l}\text { 14.Hospitality, Retail and Other Services } \\
\text { Managers }\end{array}$} & $0.294 * * *$ & $0.230 * * *$ & $\begin{array}{l}\text { 61.Market-oriented Skilled Agricultural } \\
\text { Workers }\end{array}$ & 0.018 & -0.040 \\
\hline & $(0.052)$ & $(0.053)$ & & $(0.025)$ & $(0.026)$ \\
\hline \multirow[t]{2}{*}{$\begin{array}{l}\text { 21.Science and Engineering Profession- } \\
\text { als }\end{array}$} & $0.050 * *$ & 0.012 & $\begin{array}{l}\text { 62.Market-oriented Skilled Forestry, } \\
\text { Fishery and Hunting. }\end{array}$ & 0.032 & -0.044 \\
\hline & $(0.022)$ & $(0.025)$ & & $(0.068)$ & $(0.063)$ \\
\hline \multirow[t]{2}{*}{ 22.Health Professionals } & 0.016 & 0.000 & $\begin{array}{l}\text { 63. Subsistence Farmers, Fishers, Hunt- } \\
\text { ers and Gatherers }\end{array}$ & -0.014 & -0.055 \\
\hline & $(0.017)$ & $(0.021)$ & & $(0.039)$ & $(0.038)$ \\
\hline \multirow[t]{2}{*}{$\begin{array}{l}\text { 24.Business and Administration Profes- } \\
\text { sionals }\end{array}$} & 0.014 & -0.011 & $\begin{array}{l}\text { 71.Building and Related Trades Workers } \\
\text { (excluding Electr..) }\end{array}$ & $0.134 * * *$ & $0.063 * *$ \\
\hline & $(0.021)$ & $(0.024)$ & & $(0.029)$ & $(0.031)$ \\
\hline \multirow[t]{2}{*}{$\begin{array}{l}\text { 25.Information and Communications } \\
\text { Technology Professionals }\end{array}$} & $0.093 * *$ & 0.072 & $\begin{array}{l}\text { 72.Metal, Machinery and Related Trades } \\
\text { Workers }\end{array}$ & $0.194 * * *$ & $0.147 * * *$ \\
\hline & $(0.042)$ & $(0.047)$ & & $(0.030)$ & $(0.034)$ \\
\hline \multirow{2}{*}{$\begin{array}{l}\text { 26.Legal, Social and Cultural Profes- } \\
\text { sionals }\end{array}$} & $0.065^{* * *}$ & $0.046^{*}$ & 73.Handicraft and Printing Workers & $0.275^{* * *}$ & $0.233 * * *$ \\
\hline & $(0.021)$ & $(0.025)$ & & $(0.057)$ & $(0.061)$ \\
\hline \multirow[t]{2}{*}{$\begin{array}{l}\text { 31.Science and Engineering Associate } \\
\text { Professionals }\end{array}$} & $0.116^{* * *}$ & $0.091 * * *$ & $\begin{array}{l}\text { 74.Electrical and Electronic Trades } \\
\text { Workers }\end{array}$ & $0.142 * * *$ & $0.116^{* * *}$ \\
\hline & $(0.027)$ & $(0.030)$ & & $(0.042)$ & $(0.044)$ \\
\hline \multirow[t]{2}{*}{ 32.Health Associate Professionals } & $0.110^{* * *}$ & $0.093 * * *$ & $\begin{array}{l}\text { 75.Food Processing, Woodworking, Gar- } \\
\text { ment and Other Craft. }\end{array}$ & $0.170 * * *$ & $0.116^{* * *}$ \\
\hline & $(0.030)$ & $(0.034)$ & & $(0.031)$ & $(0.034)$ \\
\hline \multirow[t]{2}{*}{$\begin{array}{l}\text { 33. Business and Administration Associ- } \\
\text { ate Professionals }\end{array}$} & $0.073 * * *$ & $0.049 * *$ & $\begin{array}{l}\text { 81.Stationary Plant and Machine Opera- } \\
\text { tors }\end{array}$ & $0.129 * * *$ & $0.092 * *$ \\
\hline & $(0.018)$ & $(0.022)$ & & $(0.035)$ & $(0.038)$ \\
\hline \multirow{2}{*}{$\begin{array}{l}\text { 34.Legal, Social, Cultural and Related } \\
\text { Associate Professi. }\end{array}$} & $0.115^{* *}$ & $0.091 * *$ & 82.Assemblers & $0.141 * *$ & 0.104 \\
\hline & $(0.036)$ & $(0.041)$ & & $(0.063)$ & $(0.065)$ \\
\hline \multirow{2}{*}{$\begin{array}{l}\text { 35.Information and Communications } \\
\text { Technicians }\end{array}$} & $0.166^{* * *}$ & $0.135 * *$ & 83.Drivers and Mobile Plant Operators & $0.182 * * *$ & $0.144 * * *$ \\
\hline & $(0.064)$ & $(0.064)$ & & $(0.027)$ & $(0.031)$ \\
\hline \multirow[t]{2}{*}{ 41.General and Keyboard Clerks } & $0.037 * *$ & 0.015 & 91.Cleaners and Helpers & $0.160 * * *$ & $0.122 * * *$ \\
\hline & $(0.019)$ & $(0.023)$ & & $(0.025)$ & $(0.029)$ \\
\hline \multirow[t]{2}{*}{ 42.Customer Services Clerks } & $0.108 * * *$ & $0.090 * *$ & $\begin{array}{l}\text { 92.Agricultural, Forestry and Fishery } \\
\text { Labourers }\end{array}$ & $0.141 * *$ & 0.061 \\
\hline & $(0.035)$ & $(0.039)$ & & $(0.066)$ & $(0.059)$ \\
\hline \multirow[t]{2}{*}{$\begin{array}{l}\text { 43.Numerical and Material Recording } \\
\text { Clerks }\end{array}$} & $0.089 * * *$ & $0.057 *$ & $\begin{array}{l}\text { 93.Labourers in Mining, Construction, } \\
\text { Manufacturing and T. }\end{array}$ & $0.152 * * *$ & $0.111^{* * *}$ \\
\hline & $(0.027)$ & $(0.030)$ & & $(0.031)$ & $(0.034)$ \\
\hline 44.Other Clerical Support Workers & $0.061 *$ & 0.057 & 94.Food Preparation Assistants & $0.341 * * *$ & $0.327 * * *$ \\
\hline
\end{tabular}


Table 4 (continued)

\begin{tabular}{|c|c|c|c|c|c|}
\hline & Baseline model & Full model & (continue) & Baseline model & Full model \\
\hline & $(0.031)$ & $(0.038)$ & & $(0.065)$ & $(0.070)$ \\
\hline \multirow[t]{2}{*}{ 51.Personal Service workers } & $0.295 * * *$ & $0.243 * * *$ & $\begin{array}{l}\text { 95.Street and Related Sales and Services } \\
\text { Workers }\end{array}$ & $0.389 * *$ & 0.223 \\
\hline & $(0.027)$ & $(0.030)$ & & $(0.175)$ & $(0.179)$ \\
\hline \multirow[t]{2}{*}{ 52.Sales Workers } & $0.180 * * *$ & $0.130 * * *$ & $\begin{array}{l}\text { 96.Refuse Workers and Other Elemen- } \\
\text { tary Workers }\end{array}$ & $0.064 *$ & 0.039 \\
\hline & $(0.024)$ & $(0.027)$ & & $(0.038)$ & $(0.044)$ \\
\hline
\end{tabular}

Data: Preliminary SHARE wave 8 release 0 . Conclusions are preliminary.

Notes: Average marginal effects of probit models are reported. Baseline model: 7619 (observations), 0.121 (Pseudo R2), - 3143,11 (Log pseudolikelihood). Full model: 6878 (observations), 0.1316 (Pseudo R2), - 2835.22 (Log pseudolikelihood)

$* p<0.1, * * p<0.05, * * * p<0.01$

stop (column 1 of each specification), with respect to the "unessential" ones. In relative terms, being employed in an essential activity determines a reduction in the probability of a brief or long interruption of about $12.15 \%$ and $22.22 \%$, respectively. Instead, the magnitude of the effect when considering the probability of zero weeks of interruption is much smaller, i.e. no interruptions at all $(+3.53 \%)$. Jobs with high suitability to remote work display significantly lower probabilities of longer work breaks, while those with a large intensity of social interactions have higher likelihoods of prolonged interruptions. The results are consistent with those found in the estimation of the probability of stopping work. As a robustness check, we also perform a Tobit regression model using the number of weeks of interruption as a continuous dependent variable. The results support our findings and are available as supplementary information.

Additional insights into the impact of job features and their magnitude are provided by Figs. 5 and 6: they show the average marginal effects of an essential occupation on the probability of having experienced 0,1 to 8 and more than 8 weeks of work interruption at different values of the two indexes. Workers employed in "essential" occupations unsuited to remote work (index values smaller than 0.5 ) display a significantly lower probability of having prolonged work interruptions with respect to workers performing "unessential" jobs. Such a difference vanishes as home work feasibility increases. A similar impact-but opposite in sign-is observed for the social interaction index: jobs characterised by intensive social contacts but regarded as "crucial" in society, reveal a reduction in the likelihood of experiencing longer work interruptions with respect to nonessential ones. This effect disappears at lower values of the social interaction index.

In addition to the previous finding, our results add salient evidence on several other issues. We find that education has a clear mitigating role for the negative labour market effects of the Pandemic, even when controlling for occupation features. Respondents holding higher levels of education (vis-a-vis the reference category "high school degree") display a 3.5 percentage points lower likelihood of work interruption and about 2 percentage points smaller probability of undergoing prolonged interruption spells. We speculate that educational attainment plays a relevant role per se, both because workers with higher education are often associated with "higher quality jobs", and also because education is related to the specific tasks required in a job. The idea is that the human capital of highly educated workers may be more flexible in terms of tasks performed. By recalling the basic characteristics defined by Autor and Dorn, 2009, Autor and Dorn 2013 and Deming 2017, the exogenous shock generated by the Pandemic has probably affected more jobs involving tasks of high routine intensity, i.e. tasks that involve a well-defined repetitive set of procedures. In fact, during economic downturns, sizeable employment losses mainly appear among the more routine-intensive middleskilled occupations, some of these jobs eventually disappear and are not retrieved when the economy recovers (Jaimovich and Siu, 2020).

Finally, our results also highlight differences between workers in different types of employment. With respect to the baseline category of the private employees, public employees were 8.3 percentage points less likely to have experienced work interruption whereas self-employed workers had significantly larger probabilities of such an event. Moreover, public sector employees are characterised by a 4.1 percentage points lower probability of having experienced work interruptions between 1 and 8 weeks, and 4.2 percentage points smaller likelihood of breaks longer than 8 weeks. We find an opposite and significant effect for selfemployed workers.

\section{A focus on women}

The previous models allow us to address several questions that are currently the object of debate for researchers and policy makers. Did women pay a higher price than men 
Table 5 Ordered probit model: length of work interruption

\begin{tabular}{|c|c|c|c|c|c|c|}
\hline & \multicolumn{3}{|c|}{ Length of work interruption } & \multicolumn{3}{|c|}{ Length of work interruption } \\
\hline & 0 weeks & weeks & $>8$ weeks & 0 weeks & $1-8$ weeks & $>8$ weeks \\
\hline Essential Jobs & $\begin{array}{l}0.057 * * * \\
(0.009)\end{array}$ & $\begin{array}{l}-0.027 * * * \\
(0.004)\end{array}$ & $\begin{array}{l}-0.029 * * * \\
(0.004)\end{array}$ & $\begin{array}{l}0.029 * * * \\
(0.010)\end{array}$ & $\begin{array}{l}-0.013 * * * \\
(0.005)\end{array}$ & $\begin{array}{l}-0.016^{* * *} \\
(0.005)\end{array}$ \\
\hline Remote work feasibility index & $\begin{array}{l}0.113 * * * \\
(0.012)\end{array}$ & $\begin{array}{l}-0.054^{* * * *} \\
(0.006)\end{array}$ & $\begin{array}{l}-0.059 * * * \\
(0.006)\end{array}$ & $\begin{array}{l}0.074 * * * \\
(0.013)\end{array}$ & $\begin{array}{l}-0.034 * * * \\
(0.006)\end{array}$ & $\begin{array}{l}-0.039^{* * *} \\
(0.007)\end{array}$ \\
\hline Social interaction index & $\begin{array}{l}-0.012 \\
(0.013)\end{array}$ & $\begin{array}{l}0.005 \\
(0.006)\end{array}$ & $\begin{array}{l}0.007 \\
(0.007)\end{array}$ & $\begin{array}{c}-0.037^{* *} \\
(0.014)\end{array}$ & $\begin{array}{l}0.017 * * \\
(0.007)\end{array}$ & $\begin{array}{l}0.020 * * * \\
(0.008)\end{array}$ \\
\hline Age & $\begin{array}{l}-0.001 \\
(0.001)\end{array}$ & $\begin{array}{l}0,001 \\
(0.0004)\end{array}$ & $\begin{array}{l}0.001 \\
(0.0004)\end{array}$ & $\begin{array}{r}-0.001 \\
(0.001)\end{array}$ & $\begin{array}{l}0.0003 \\
(0.0005)\end{array}$ & $\begin{array}{l}0.0003 \\
(0.001)\end{array}$ \\
\hline Female & $\begin{array}{l}-0.023^{* * *} \\
(0.009)\end{array}$ & $\begin{array}{l}0.011 * * * \\
(0.004)\end{array}$ & $\begin{array}{l}0.012 * * * \\
(0.005)\end{array}$ & $\begin{array}{c}-0.039 * * * \\
(0.009)\end{array}$ & $\begin{array}{l}0.018 * * * \\
(0.004)\end{array}$ & $\begin{array}{l}0.021 * * * \\
(0.005)\end{array}$ \\
\hline \multicolumn{7}{|l|}{ High School Education (baseline) } \\
\hline Less than high school & - & - & - & $\begin{array}{r}-0.025^{*} \\
(0.015)\end{array}$ & $\begin{array}{l}0.011^{*} \\
(0.007)\end{array}$ & $\begin{array}{l}0.014^{*} \\
(0.008)\end{array}$ \\
\hline Higher than high school & $\begin{array}{l}- \\
-\end{array}$ & $\begin{array}{l}- \\
-\end{array}$ & - & $\begin{array}{l}0.038 * * * \\
(0.010)\end{array}$ & $\begin{array}{l}-0.018^{* * * *} \\
(0.005)\end{array}$ & $\begin{array}{l}-0.020^{* * *} \\
(0.005)\end{array}$ \\
\hline Major illness & - & $\begin{array}{l}- \\
-\end{array}$ & - & $\begin{array}{r}-0.029^{*} \\
(0.017)\end{array}$ & $\begin{array}{l}0.013^{*} \\
(0.008)\end{array}$ & $\begin{array}{l}0.016 \\
(0.010)\end{array}$ \\
\hline \multicolumn{7}{|l|}{ Medium level of IT- skills (baseline) } \\
\hline High IT - skills & - & $\begin{array}{l}- \\
-\end{array}$ & $\begin{array}{l}- \\
-\end{array}$ & $\begin{array}{c}0.004 \\
(0.011)\end{array}$ & $\begin{array}{l}-0.002 \\
(0.005)\end{array}$ & $\begin{array}{l}-0.002 \\
(0.006)\end{array}$ \\
\hline Low IT- skills & $\begin{array}{l}- \\
-\end{array}$ & $\begin{array}{l}- \\
-\end{array}$ & $\begin{array}{l}- \\
-\end{array}$ & $\begin{array}{r}-0.001 \\
(0.012)\end{array}$ & $\begin{array}{l}0.0003 \\
(0.006)\end{array}$ & $\begin{array}{l}0.0004 \\
(0.007)\end{array}$ \\
\hline Private Employee (baseline) & - & - & - & & & \\
\hline Public employee & $\begin{array}{l}- \\
-\end{array}$ & $\begin{array}{l}- \\
-\end{array}$ & - & $\begin{array}{l}0.083 * * * \\
(0.010)\end{array}$ & $\begin{array}{l}-0.042 * * * \\
(0.005)\end{array}$ & $\begin{array}{l}-0.041^{* * *} \\
(0.005)\end{array}$ \\
\hline Self- employed & $\begin{array}{l}- \\
-\end{array}$ & $\begin{array}{l}- \\
-\end{array}$ & $\begin{array}{l}- \\
-\end{array}$ & $\begin{array}{c}-0.060 * * * \\
(0.015)\end{array}$ & $\begin{array}{l}0.025 * * * \\
(0.006)\end{array}$ & $\begin{array}{l}0.034 * * * \\
(0.009)\end{array}$ \\
\hline Essential_RemoteWorkIndex & Yes & & & Yes & & \\
\hline Essential_SocialInteractionIndex & Yes & & & Yes & & \\
\hline Country dummies & Yes & & & Yes & & \\
\hline $\mathrm{N}$ & 7619 & & & 6878 & & \\
\hline Pseudo-r2 & 0.0724 & & & 0.0852 & & \\
\hline Log pseudolikelihood & -4169.13 & & & -3760.93 & & \\
\hline
\end{tabular}

Data: Preliminary SHARE wave 8 release 0 . Conclusions are preliminary. Notes: Average marginal effects of probit models are reported. Drop of observations in full model due to missing values in additional explanatory variables

$* p<0.1, * * p<0.05, * * * p<0.01$

in terms of work interruptions during the Pandemic? Are there heterogeneities in terms of job characteristics useful to build more targeted (and potentially more effective) support measures?

By recalling that particular care should be paid in drawing general conclusions-our sample looks at workers aged 50 and over-we attempt to provide answers to the above questions. When introducing a "female dummy" in the above models, we find that women in our age groups are more likely to experience work interruptions with respect to men (about 3.9 percentage points more), and longer work breaks (by $1.8 \mathrm{pp}$ more for interruptions between 1 to 8 weeks, and by $2.1 \mathrm{pp}$ more for episodes longer than 8 weeks). In relative terms, women have been $21.79 \%$ more likely to experience working breaks than men. Moreover, by looking at the duration of such interruptions, they also display higher probabilities of short and long breaks of about $+16.5 \%$ and $+29.16 \%$, respectively. In order to get further insights, we run the regressions separately by gender. Table 6 reports the results of these estimations both for the probability and for the length of work interruptions. 
Fig. 5 Length of work interruption: average marginal effects of working in essential jobs at different level of the remote work feasibility index

Fig. 6 Length of work interruption: average marginal effects of working in essential jobs at different level of the social interaction index

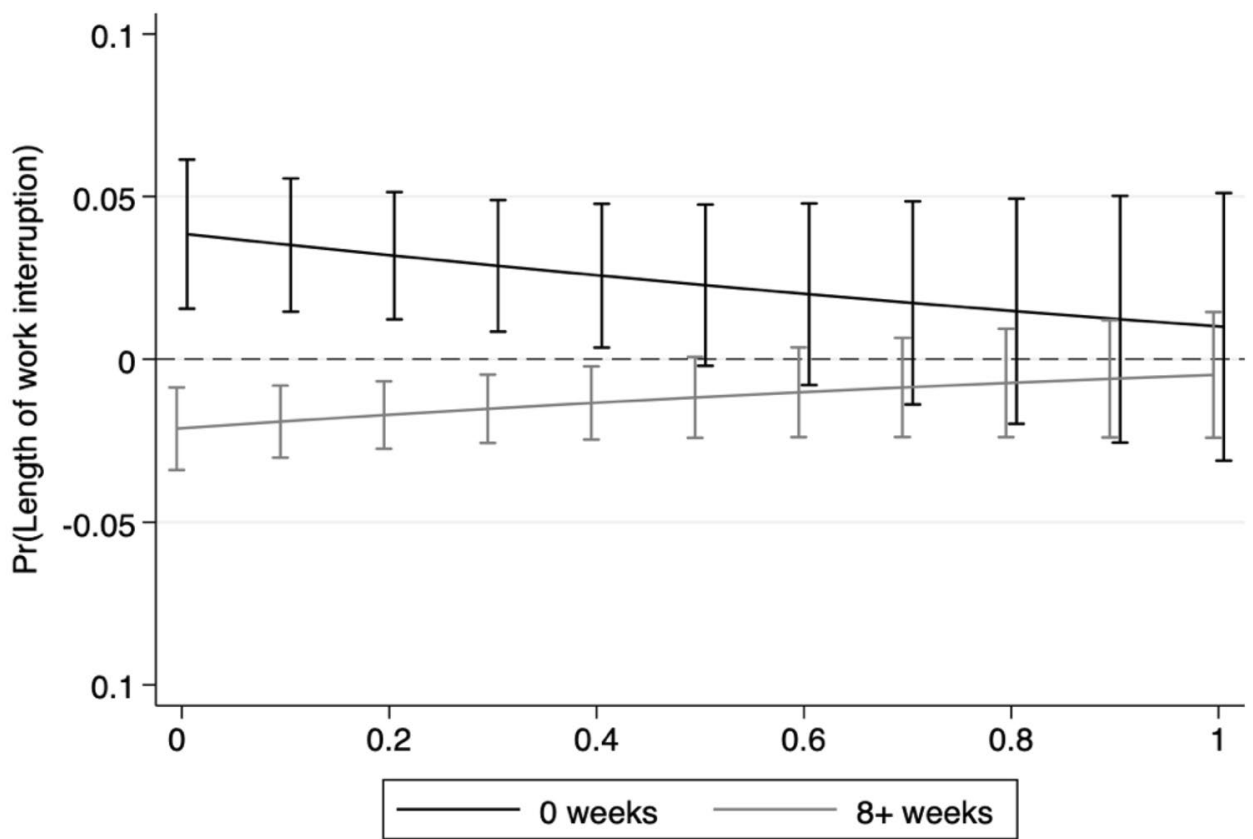

Source: Preliminary data SHARE wave 8 release 0 . Conclusions are preliminary. Notes: $95 \% \mathrm{Cl}$

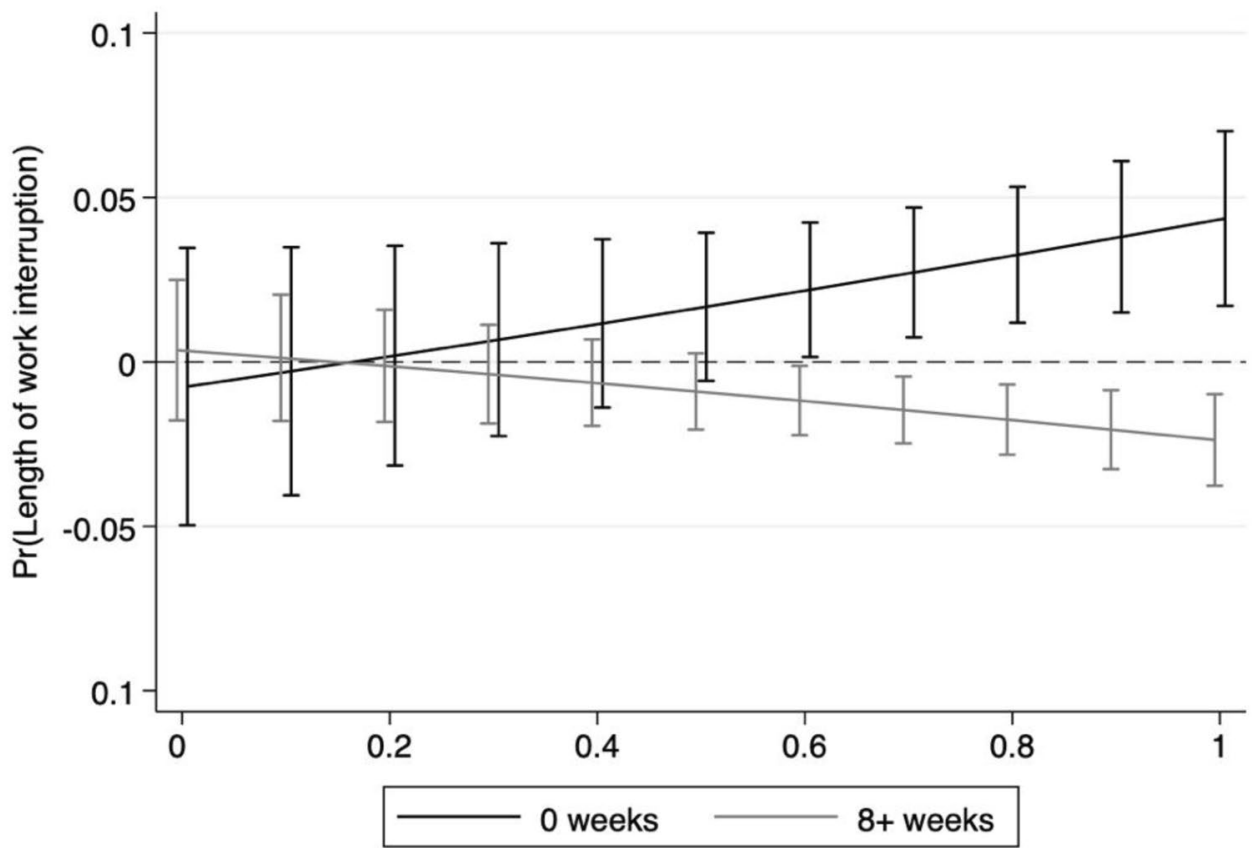

Source: Preliminary data SHARE wave 8 release 0 . Conclusions are preliminary. Notes: $95 \% \mathrm{CI}$
It is easy to observe that a large part of the effect captured in all the main specifications by the essential nature of a job is mostly driven by women. Female workers employed in essential activities are 5.7 percentage points less likely to experience interruptions than those employed in nonessential ones. Differently, male workers seem more vulnerable as the level of social interaction at the usual workplace increases. As expected, the remote work feasibility of a job has been a crucial determinant during the first wave of the COVID-19 Pandemic, irrespective of gender. Figs 7, 8, 9, 10 depict the average marginal effects of being employed in essential occupations (with respect to non-essential ones) at different levels of remote work feasibility and social interaction, for men and women separately. The first type of interaction points out the home work feasibility as the prevailing dimension among women: at lower levels of the remote 
Table 6 Probability of a work interruption and its length by gender

\begin{tabular}{|c|c|c|c|c|c|c|c|c|}
\hline & \multicolumn{2}{|c|}{ Work Interruption } & \multicolumn{6}{|c|}{ Length of work interruption } \\
\hline & & & 0 weeks & & 1 to 8 weeks & & More than 8 & \\
\hline & Women & Men & Women & Men & Women & Men & Women & Men \\
\hline \multirow[t]{2}{*}{ Essential Jobs } & $0.057 * * *$ & -0.008 & $0.051 * * *$ & 0.006 & $-0.023 * * *$ & -0.003 & $-0.027 * * *$ & -0.003 \\
\hline & $(0.014)$ & $(0.015)$ & $(0.014)$ & $(0.015)$ & $(0.007)$ & $(0.007)$ & $(0.007)$ & $(0.008)$ \\
\hline \multirow[t]{2}{*}{ Remote work feasibility index } & $-0.085^{* * *}$ & $-0.057 * * *$ & $0.083 * * *$ & $0.049 * *$ & $-0.038 * * *$ & $-0.023 * *$ & $-0.045^{* * *}$ & $-0.026^{* *}$ \\
\hline & $(0.019)$ & $(0.020)$ & $(0.018)$ & $(0.020)$ & $(0.009)$ & $(0.009)$ & $(0.010)$ & $(0.010)$ \\
\hline \multirow[t]{2}{*}{ Social interaction index } & 0.034 & $0.045^{* *}$ & $-0.037^{*}$ & $-0.044 * *$ & 0.016 & $0.021 * *$ & $0.022 *$ & $0.023^{* *}$ \\
\hline & $(0.021)$ & $(0.021)$ & $(0.021)$ & $(0.020)$ & $(0.010)$ & $(0.010)$ & $(0.011)$ & $(0.011)$ \\
\hline Essential_RemoteWorkIndex & Yes & Yes & Yes & Yes & Yes & Yes & Yes & Yes \\
\hline $\begin{array}{l}\text { Essential_SocialInteractionIn- } \\
\text { dex }\end{array}$ & Yes & Yes & Yes & Yes & Yes & Yes & Yes & Yes \\
\hline Country dummies & Yes & Yes & Yes & Yes & Yes & Yes & Yes & Yes \\
\hline Additional covariates & Yes & Yes & Yes & Yes & Yes & Yes & Yes & Yes \\
\hline $\mathrm{N}$ & 3839 & 3039 & 3839 & 3039 & 3839 & 3039 & 3839 & 3039 \\
\hline Pseudo-r2 & 0.1328 & 0.1109 & 0.1049 & 0.0839 & 0.1049 & 0.0839 & 0.1049 & 0.0839 \\
\hline Log pseudolikelihood & -1595.32 & -1266.96 & -2077.20 & -1640.01 & -2077.20 & -1640.01 & -2077.20 & -1640.01 \\
\hline
\end{tabular}

Data: Preliminary SHARE wave 8 release 0 . Conclusions are preliminary.

Notes: Average marginal effects of probit and ordered probit full models are reported. Variables "Essential_RemoteWorkIndex" and "Essential_SocialInteractionIndex" are the interaction terms.

$* \mathrm{p}<0.1, * * \mathrm{p}<0.05, * * \mathrm{p}<0.01$

Fig. 7 Work interruption probability by gender: average marginal effects of working in essential jobs at different levels of the remote work feasibility index

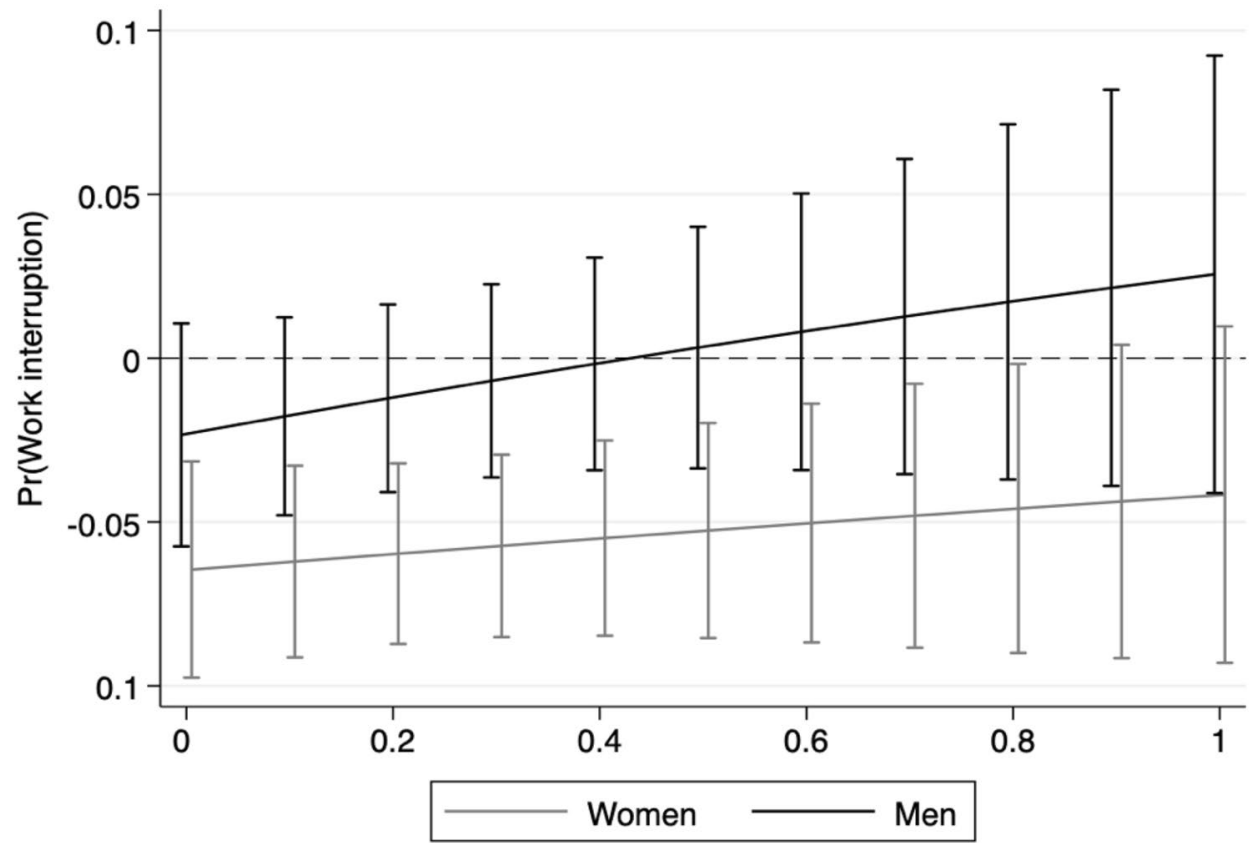

Source: Preliminary data SHARE wave 8 release 0 . Conclusions are preliminary. Notes: $95 \% \mathrm{Cl}$ work feasibility index the essentiality of tasks performed by women is highly significant to avoid work interruptions as well as longer breaks, while this is not the case for men. As regards our second index, for high levels of social interaction at work, the essential nature of an occupation represents a deterrent against job interruption mainly for women, while the opposite is found for men.

Several aspects such as gender and age composition of specific jobs can partially explain the previous results. For instance, the prevalence of women tends to be higher 
Fig. 8 Work interruption probability by gender: average marginal effects of working in essential jobs at different levels of the social interaction index

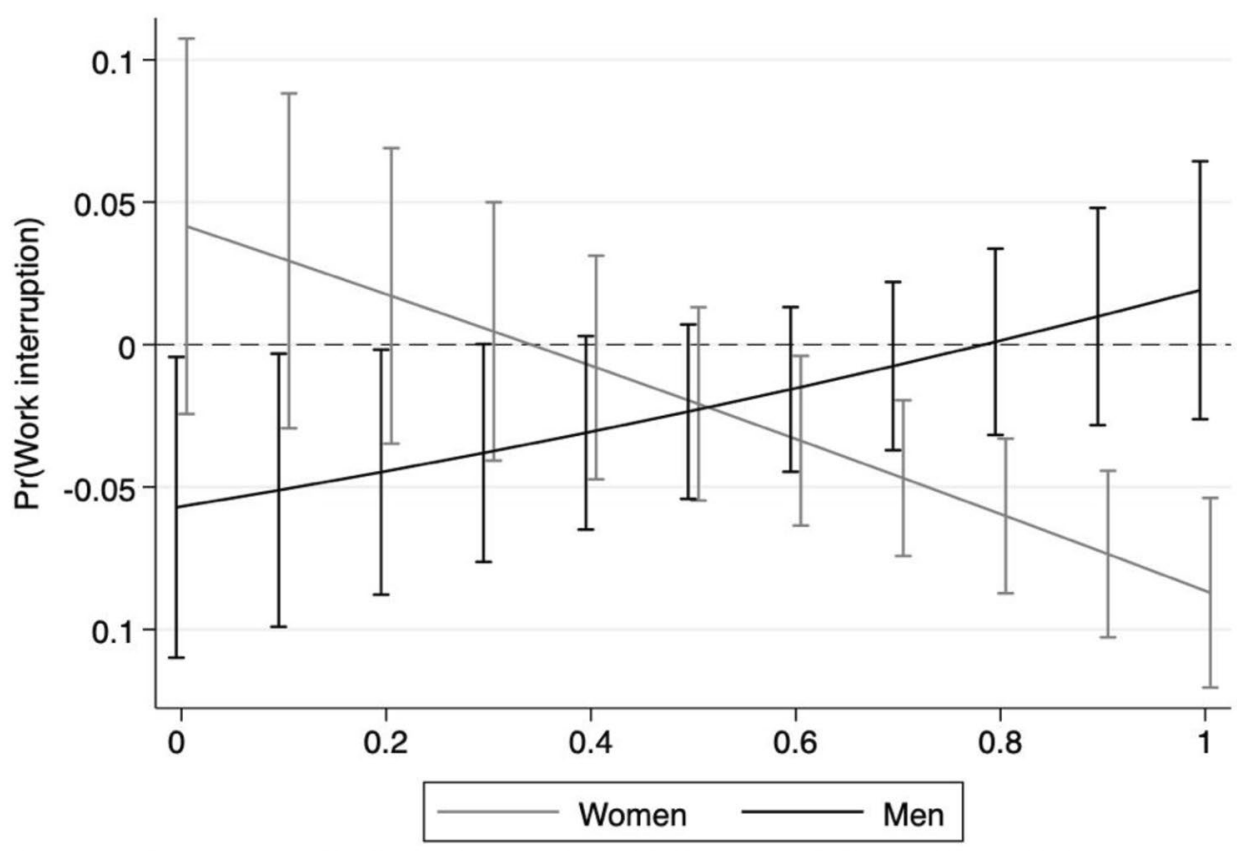

Source: Preliminary data SHARE wave 8 release 0 . Conclusions are preliminary. Notes: $95 \% \mathrm{Cl}$

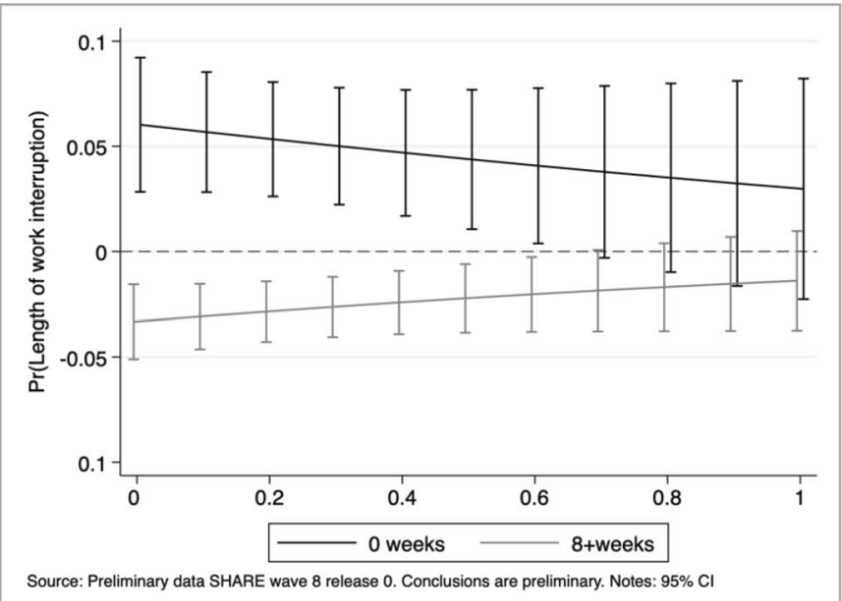

Source: Preliminary data SHARE wave 8 release 0 . Conclusions are preliminary. Notes: $95 \% \mathrm{CI}$

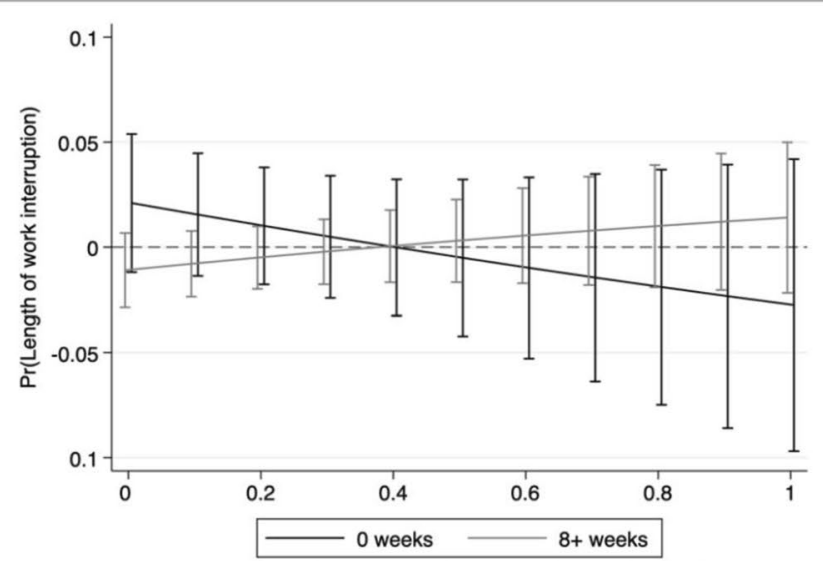

Source: Preliminary data SHARE wave 8 release 0. Conclusions are preliminary. Notes: $95 \% \mathrm{Cl}$

Fig. 9 Length of work interruption by gender: average marginal effects of working in essential jobs at different levels of the remote work feasibility index for women (left panel) and men (right panel)

among essential but more exposed to contagion (intensive social interaction) activities (i.e. nursing and midwifery professionals (222) or primary school and early childhood teachers (234)), while male workers prevail among essential but lower risk occupations (i.e. heavy truck and bus drivers (833) or mixed crop and animal producers (613)). No less important is the role played by intergenerational differences and thus, the representativeness of our sample of
$50+$ workers: the gender selection into specific jobs-more or less demanding in terms of tasks-might be highly pronounced among older cohorts compared to younger ones.

Overall, the previous findings show that the negative effects of the Pandemic on workers were harsher on women. However, the results also reveal that gender differences in labour market outcomes are driven by the intrinsic characteristics of the jobs/ occupations they are involved in. 

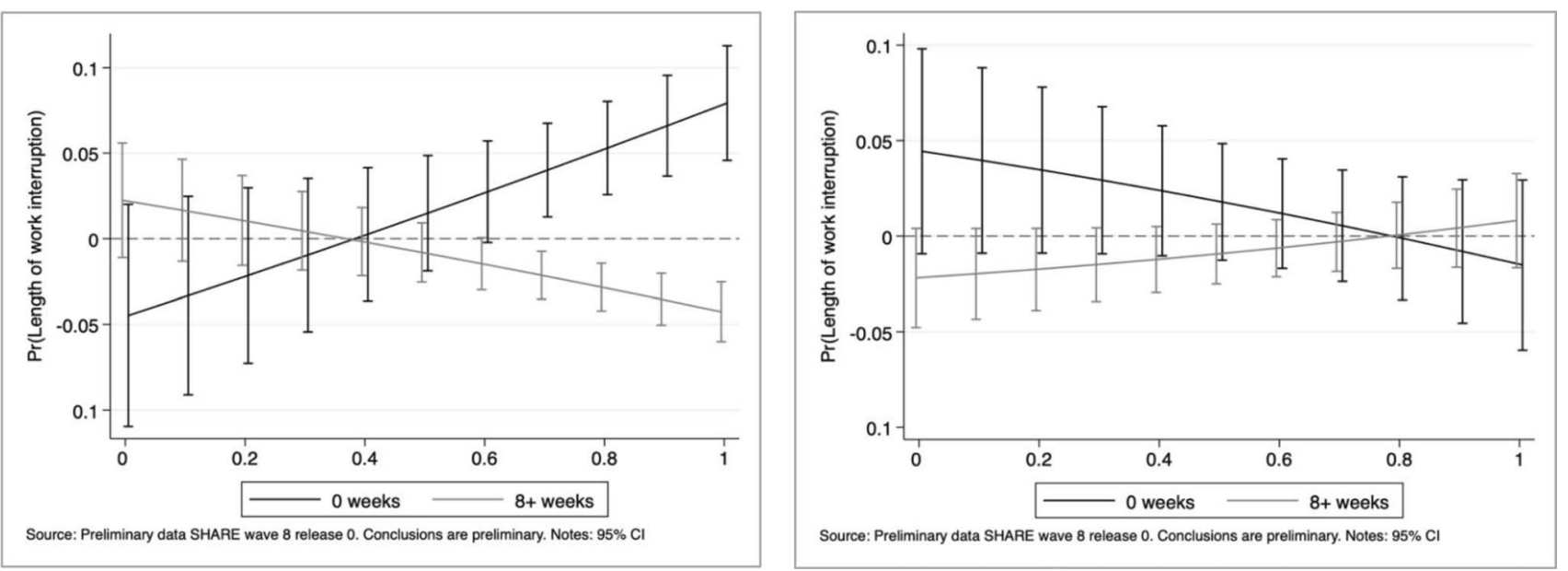

Fig. 10 Length of work interruption by gender: average marginal effects of working in essential jobs at different levels of the social interaction index for women (left panel) and men (right panel)

\section{Conclusions}

This paper evaluates the impact of job characteristics on an important labour market issue, which emerged during the COVID-19 Pandemic: the probability of having experienced work interruptions, coupled with the length of such interruptions. Assessing the determinants of these labour market outcomes is of great policy relevance as suitable interventions can be designed to prevent important economic consequences at individual level and welfare losses for the European society at large. The key finding of our research effort is that job characteristics play a major role for workers aged 50 and over in Europe, even when controlling for other relevant determinants of labour supply, such as education, geographical location and the traditional demographic and "human capital" variables used in the literature.

The novelty of our paper rests on the richness of the SHARE data, which allows us to retrieve information on panel respondents before the COVID-19 outbreak and to relate such information to the reported level of activity during the lockdowns. The most salient feature of our work is the use of the newly coded occupations reported in SHARE and classified according to their ISCO-08 3 -digit code. The level of detail provided by the occupational classification allows us to characterize the jobs based on several dimensions, by enabling us to generate two measures, extremely relevant under the Pandemic scenario: the suitability to remote work and the level of social interaction when performing the tasks in normal conditions. As an additional important aspect, we also distinguish between essential and unessential nature of the job. A further important feature of the SHARE data is the heterogeneity across countries, so that we benefit from the variability in labour markets arrangements/lockdowns across all SHARE countries during the Pandemic.

We find that for workers in the age group 50 and over, all the occupations dimensions considered played a major role in determining both the probability of working continuously during the Pandemic and the length of work breaks. Workers who experienced more work interruption (and longer breaks) were mainly engaged in "unessential" occupations that were either not suited to be performed remotely or involved intensive social contacts/low physical proximity. For reasonable large levels of the remote work feasibility index or small social interaction index, the difference in the likelihood of undergoing work breaks between essential and unessential jobs vanishes. A clear policy implication of our finding is that labour market arrangements should facilitate the more vulnerable jobs, devoting more resources to increasing the safety of these occupations, whenever possible.

Furthermore, non-essential occupations are characterized by longer job interruptions, possibly ending up into longterm unemployment experiences, which could jeopardize the chances for these workers to return to the labour market after the end of the crisis. Policies aimed at protecting work during the Pandemic should prioritize occupational groups which are more at risk of suffering these long-term consequences.

Our findings point to a number of possible research lines on how to improve the resilience of jobs in face of negative shocks, such as the COVID-19 Pandemic. One possible implication is that employers and institutions might need to plan a more careful organization at the workplace, paying attention to the nature of the tasks performed, so that 
it might be necessary to re-design the production process enlarging the notion of "risks" in performing a job.

In addition, our results contribute to an ongoing debate on gender differences in labour market outcomes. Women aged 50 and over have been more heavily affected by the Pandemic because they are more likely to experience job interruptions and for longer periods. A possible explanation supported by our data is that jobs which rely on close physical interaction with customers, such as, retail activities, accommodation or services to the person and which have been hit harder by the recent sanitary situation, are performed mainly by women. Our results help disentangling an important dilemma: on the one hand, women are more exposed to negative labour market experience, but, on the other hand, because they are more likely to work in the public sector, they are less affected by the negative COVID-19 shock (OECD, 2020b). We show that even controlling for the sector of employment, women are more likely to experience job interruptions and confirm that women represent a particularly "vulnerable group" as far as the labour market risk is concerned. So, it is possible that labour market arrangements which improve the safety of jobs -in the way we have defined them - could also help older women in enlarging the set of choices that would make it possible to keep on working.

Supplementary Information The online version contains supplementary material available at https://doi.org/10.1007/s10433-021-00651-5.

\begin{abstract}
Acknowledgements This publication is based on preliminary SHARE wave 8 release 0 data (Börsch-Supan 2020). Therefore, the analyses, conclusions and results are preliminary. Please see Scherpenzeel et al. (2020) for methodological details. In addition, this paper uses data from SHARE Waves 1, 2, 3, 4, 5, 6 and 7 (DOI: 10.6103/SHARE.w1.710, 10.6103/SHARE.w2.710, 10.6103/SHARE.w3.710, 10.6103/SHARE. w4.710, 10.6103/SHARE.w5.710, 10.6103/SHARE.w6.710, 10.6103/ SHARE.w7.710), see Börsch-Supanet al. (2013) for methodological details. The SHARE data collection has been funded by the European Commission through FP5 (QLK6-CT-2001-00360), FP6 (SHARE-I3: RII-CT-2006-062193, COMPARE: CIT5-CT-2005-028857, SHARELIFE: CIT4-CT-2006-028812), FP7 (SHARE-PREP: GA N²11909, SHARE-LEAP: GA N`227822, SHARE M4: GA N`261982, DASISH: GA N ${ }^{\circ} 283646$ ) and Horizon 2020 (SHARE-DEV3: GA N ${ }^{\circ} 676536$, SHARE-COHESION: GA N ${ }^{\circ} 870628$ SERISS: GA N ${ }^{\circ} 654221$, SSHOC: GA N ${ }^{\circ} 823782$ ) and by DG Employment, Social Affairs \& Inclusion. Additional funding from the German Ministry of Education and Research, the Max Planck Society for the Advancement of Science, the U.S. National Institute on Aging (U01_AG09740-13S2, P01_ AG005842, P01_AG08291, P30_AG12815, R21_AG025169, Y1-AG4553-01, IAG_BSR06-11, OGHA_04-064, HHSN271201300071C) and from various national funding sources is gratefully acknowledged, (see www.share-project.org).
\end{abstract}

Funding Open access funding provided by Università Ca' Foscari Venezia within the CRUI-CARE Agreement. SHARE-COHESION: GA $\mathrm{N}^{\circ}$ 870628SERISS: GA Nº54221, SHARE-COVID19.

Data availability SHARE data are available on the official SHAREproject website, www.share-project.org, upon registration.

\section{Declarations}

Conflict of interest The authors declare that they have no conflict of interest.

Open Access This article is licensed under a Creative Commons Attribution 4.0 International License, which permits use, sharing, adaptation, distribution and reproduction in any medium or format, as long as you give appropriate credit to the original author(s) and the source, provide a link to the Creative Commons licence, and indicate if changes were made. The images or other third party material in this article are included in the article's Creative Commons licence, unless indicated otherwise in a credit line to the material. If material is not included in the article's Creative Commons licence and your intended use is not permitted by statutory regulation or exceeds the permitted use, you will need to obtain permission directly from the copyright holder. To view a copy of this licence, visit http://creativecommons.org/licenses/by/4.0/.

\section{References}

Autor D, Dorn D (August 2013) The growth of low-skill service jobs and the polarization of the US labor market. American Economic Review 103(5):1553-97

Autor D, Dorn D (2009) This job is "getting old": measuring changes in job opportunities using occupational age structure. American Economic Review 99(2):45-51

Barbieri T., Basso G. and Scicchitano S. (2020), "Italian Workers at Risk During the Covid-19 Epidemic", INAPP working paper, 46.

Basso G., Boeri T., Caiumi A. and Paccagnella M. (2020), "The New Hazardous Jobs and Worker Reallocation”, OECD, Social, Employment and Migration Working Papers No.247

Boeri T., Caiumi A. and Paccagnella M. (2020), "Mitigating the worksafety trade-off. Covid Economics: Vetted and Real-Time Papers" 2: 60-66.

Börsch-Supan A. (2020) Survey of Health, Ageing and Retirement in Europe (SHARE) Wave 8. Release version: 0. SHARE-ERIC. Preliminary data set.

Börsch-Supan A, Brandt M, Hunkler C, Kneip T, Korbmacher J, Malter F, Schaan B, Stuck S, Zuber S (2013) Data resource profile: the survey of health, ageing and retirement in Europe (SHARE). Int J Epidemiol. https://doi.org/10.1093/ije/dyt088

Cetrulo A., Guarascio D. and Virgillito ME (2020), "The Privilege of Working from Home at the Time of Social Distancing," Intereconomics, 55(3):142'“A`1147.

Deming DJ (2017) The Growing importance of social skills in the labor market. Quarterly Journal of Economics 132(4):1593-1640

Dingel JI, Neiman B (2020) How many jobs can be done at home. Journal of Public Economics 189:104235

Fasani F., Mazza J. (2020), "Immigrant Key Workers: Their Contribution to Europe's COVID-19 Response", Policy Paper, No. 155, IZA

ILO (2020), "ILO Monitor: COVID-19 and the world of work". Third Edition, 2020

Jaimovich N, Siu HE (2020) Job polarization and jobless recoveries. Rev Econ Stat 102(1):129-147

OECD, (2020a), “OECD Employment Outlook 2020: Worker Security and the COVID-19 Crisis"

OECD, (2020b), "Women at the core of the fight against COVID-19 crisis"

Scherpenzeel A, Axt K, Bergmann M, Douhou S, Oepen A, Sand G, Schuller K, Stuck S, Wagner M, Börsch-Supan A (2020) Collecting survey data among the 50+ population during the COVID-19 
outbreak: the survey of health, ageing and retirement in Europe (SHARE). Survey Research Methods 14(2):217-221

Yasenov V. (2020), "Who can work from home?", IZA Discussion

Paper 13197, IZA
Publisher's Note Springer Nature remains neutral with regard to jurisdictional claims in published maps and institutional affiliations. 